\title{
Kalman filter physical retrieval of surface emissivity and temperature from SEVIRI infrared channels: a validation and intercomparison study
}

\author{
G. Masiello ${ }^{1}$, C. Serio ${ }^{1}$, S. Venafra ${ }^{1}$, G. Liuzzi ${ }^{1}$, F. Göttsche ${ }^{2}$, I. F. Trigo ${ }^{3}$, and P. Watts ${ }^{4}$ \\ ${ }^{1}$ Scuola di Ingegneria, Università della Basilicata, Potenza, Italy \\ ${ }^{2}$ Karlsruhe Institute of Technology (KIT), IMK-ASF, Karlsruhe, Germany \\ ${ }^{3}$ Instituto Portugues do Mar e da Atmosfera IP, Land SAF, Lisbon, Portugal \\ ${ }^{4}$ European Organisation for the Exploitation of Meteorological Satellites (EUMETSAT), Darmstadt, Germany
}

Correspondence to: C. Serio (carmine.serio@unibas.it)

Received: 24 March 2015 - Published in Atmos. Meas. Tech. Discuss.: 23 April 2015

Revised: 10 July 2015 - Accepted: 13 July 2015 - Published: 29 July 2015

\begin{abstract}
A Kalman filter-based approach for the physical retrieval of surface temperature and emissivity from SEVIRI (Spinning Enhanced Visible and Infrared Imager) infrared observations has been developed and validated against in situ and satellite observations. Validation for land has been provided based on in situ observations from the two permanent stations at Evora and Gobabeb operated by Karlsruhe Institute of Technology (KIT) within the framework of EUMETSAT's Satellite Application Facility on Land Surface Analysis (LSA SAF). Sea surface retrievals have been intercompared on a broad spatial scale with equivalent satellite products (MODIS, Moderate Resolution Imaging Spectroradiometer, and AVHRR, Advanced Very High Resolution Radiometer) and ECMWF (European Centre for MediumRange Weather Forecasts) analyses. For surface temperature, the Kalman filter yields a root mean square accuracy of $\approx$ $\pm 1.5^{\circ} \mathrm{C}$ for the two land sites considered and $\approx \pm 1.0^{\circ} \mathrm{C}$ for the sea. Comparisons with polar satellite instruments over the sea surface show nearly zero temperature bias. Over the land surface the retrieved emissivity follows the seasonal vegetation cycle and permits identification of desert sand regions using the SEVIRI channel at $8.7 \mu \mathrm{m}$ due to the strong quartz reststrahlen bands around $8-9 \mu \mathrm{m}$. Considering the two validation stations, we have found that emissivity retrieved in SEVIRI channel $10.8 \mu \mathrm{m}$ over the gravel plains of the Namibian desert is in excellent agreement with in situ observations. Over Evora, the seasonal variation of emissivity with vegetation is successfully retrieved and yields emissivity values
\end{abstract}

for green and dry vegetation that are in good agreement with spectral library data. The algorithm has been applied to the SEVIRI full disk, and emissivity maps on that global scale have been physically retrieved for the first time.

\section{Introduction}

In Masiello et al. (2013b) the authors exploited the high temporal resolution of data acquisition by geostationary satellites and their capability to resolve the diurnal cycle to develop a Kalman filter (KF) approach (e.g. Kalman, 1960; Kalman and Bucy, 1961) for the simultaneous retrieval of surface temperature, $T_{\mathrm{s}}$, and emissivity, $\epsilon$. The case of SEVIRI (Spinning Enhanced Visible and Infrared Imager) Meteosat9 high-rate level 1.5 image data was examined. It was shown that the KF approach results in an algorithm which does not need to increase the dimensionality of the data space, e.g. because of time accumulation of observations, while preserving the temporal resolution of the geostationary instrument (15 min for SEVIRI). The reliability and quality of the approach has been further demonstrated in Rozenstein et al. (2015) by applying the methodology to study the diurnal emissivity dynamics in bare versus biocrusted sand dunes in a coastal desert region.

The present study mainly focuses on the KF implementation and comparison of its results with in situ data, and other similar satellite products. As previously mentioned, 
Table 1. SEVIRI infrared channels.

\begin{tabular}{cc}
\hline SEVIRI channel number & Wavelength $(\mu \mathrm{m})$ \\
\hline 4 & 3.9 \\
5 & 6.2 \\
6 & 7.3 \\
7 & 8.7 \\
8 & 9.7 \\
9 & 10.8 \\
10 & 12.0 \\
11 & 13.4 \\
\hline
\end{tabular}

the KF approach follows the basic methodology developed by Masiello et al. (2013b). The implementation used in this study deals with surface parameters alone, namely $\left(T_{\mathrm{s}}, \epsilon\right)$. For this retrieval problem we apply a strictly temporal only method - that is, we do not consider spatial constraints.

Despite this simplification, the present KF approach is a new-concept algorithm in the broad research area of temperature-emissivity $\left(T_{\mathrm{s}}, \epsilon\right)$ retrieval from satellite, which to date relies on statistical retrieval algorithms (e.g. Li et al., 2013) and static physical schemes (e.g. Matsunga, 1994; Gillespie et al., 1998; Li et al., 2011). A distinctive aspect of our approach is that it is a dynamically, physically based approach, which makes it unique at this present time.

An in-depth assessment of the expected retrieval performance for land and sea surface and its dependence on the tuning parameters and settings of the present KF implementation has been performed and presented in Serio et al. $(2013,2014)$ and Masiello et al. (2013b), which the reader is referred to for further details. In addition, KF emissivity products have been intercompared with IASI (Infrared Atmospheric Sounding Interferometer; Hilton et al., 2012) retrievals in Masiello and Serio (2013) and Masiello et al. (2014).

The present study aims at complementing the results presented in Masiello et al. (2013b) and assessing the capability of the time dimension KF approach to provide accurate retrievals at the SEVIRI full-disk scale and in the case of long time periods, which can include large data voids because of, for example, clouds.

Towards this objective, we have set up a study to validate the KF approach on a broad spatio-temporal scale, from individual SEVIRI pixels to the SEVIRI full disk, and from days to the whole year. Validation for land has been performed based on 1-year in situ observations from the two permanent stations near Evora (Portugal) and Gobabeb (Namibia) operated by Karlsruhe Institute of Technology (KIT). For sea surface, retrievals have been intercompared with other satellite products, namely the Moderate Resolution Imaging Spectroradiometer (MODIS) and the Advanced Very High Resolution Radiometer (AVHRR). Finally, ECMWF (European Centre for Medium-Range Weather Forecasts) analyses for sea surface temperature have been compared to retrieved SEVIRI products on a timescale spanning from hours to years.
The paper is organized as follows. Section 2 is devoted to the presentation of SEVIRI and ancillary data. The basic methodology for the KF is presented in Sect. 3. The results from the validation exercise are reported in Sect. 4 and conclusions are drawn in Sect. 5.

\section{Data}

For the various case studies, which we will describe below, SEVIRI observations (Meteosat-9 high-rate SEVIRI level 1.5 image data) have been used. For cloud masking we have used the operational Meteosat Second Generation (MSG) products cloud mask. The SEVIRI imager on board Meteosat-9 allows for a complete image scan (full Earth scan) once every $15 \mathrm{~min}$ period with a spatial resolution of $3 \mathrm{~km}$ for 12 channels ( 8 in the infrared), over the full disk covering Europe, Africa and part of South America. Infrared channels range from 3.9 to $12 \mu \mathrm{m}$, and their definition in terms of channel number is given in Table 1. In order to identify and work with clear-sky radiances, the SEVIRI operational cloud mask has been used in the analysis. SEVIRI radiances and associated cloud mask were downloaded from the EUMETSAT Data Centre through the Unified Meteorological Archive Facility (UMARF).

For the present study the SEVIRI full disk is defined in such a way to include viewing zenith angles (VZA) below or equal to $70^{\circ}$. At larger angles, emissivity tends quickly to zero, whereas the SEVIRI pixel size increases. The forward model we use in the retrieval scheme assumes a plane parallel atmosphere and could be unsuitable for large zenith angles. Also, the dependence of land emissivity on the viewing angle could be an issue at VZA beyond the limit of $70^{\circ}$. It also needs to be stressed that the limit of $70^{\circ}$ is reasonable in order to work in the plane parallel approximation (e.g. Herman et al, 1994).

The area of the SEVIRI disk included within the interval $\mathrm{VZA}= \pm 70^{\circ}$ is shown in Fig. 1. This region contains some $9 \times 10^{6}$ SEVIRI pixels.

\subsection{Case study definition}

For the purpose of validation, to assess the reliability and stability of the scheme and, moreover, its capability to run on the global scale, we have defined a series of case studies, which are now presented.

\subsubsection{Single SEVIRI pixels spanning an entire year}

Individual SEVIRI pixels have been considered which correspond to two validation stations: (1) Evora station in Portugal $\left(38.55^{\circ} \mathrm{N}, 8.01^{\circ} \mathrm{E}\right)$ and (2) Gobabeb station in Namibia $\left(23.55^{\circ} \mathrm{S}\right.$ and $\left.15.18^{\circ} \mathrm{E}\right)$. The geographical location of the two stations is shown in Fig. 2. 


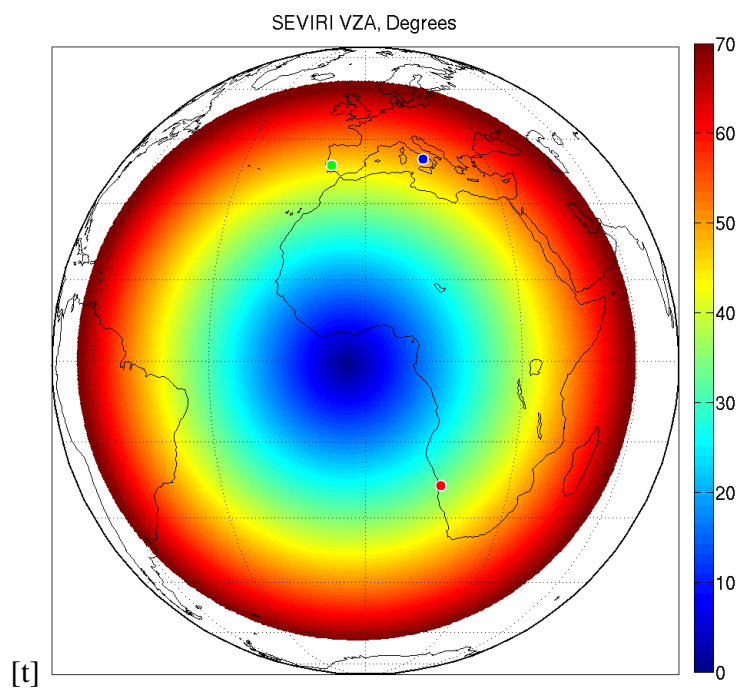

Figure 1. SEVIRI full disk according to the rule VZA (viewing zenith angle) $\leq 70^{\circ}$. The two dots over land give the location of KIT validation stations. The dot over the Mediterranean sea is the location of the SEVIRI pixel used to compare the retrieved $T_{\mathrm{S}}$ against AVHRR data.

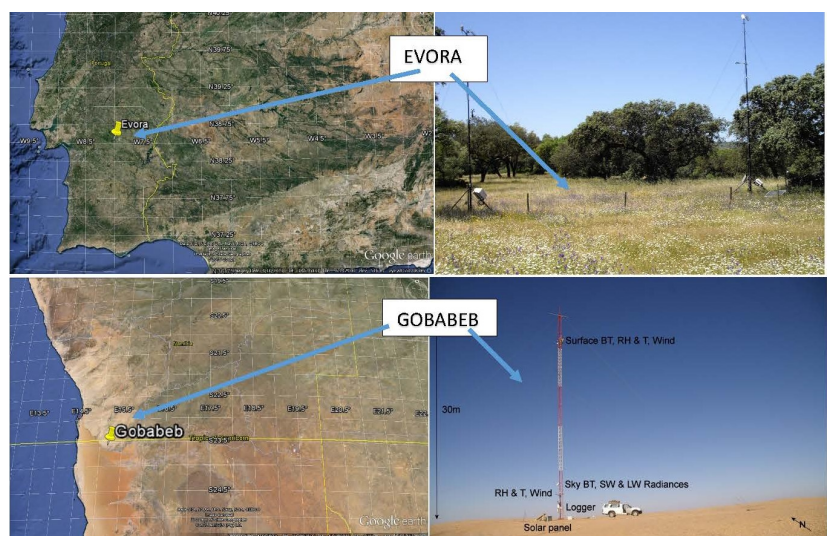

Figure 2. Evora (Portugal) and Gobabeb (Namibia) validation stations. The geographic location is shown on the left, and the landscape around the validation stations is shown on the right.

We have nearly continuous records available of in situ measurements of surface temperature for both stations. The year 2010 has been used for the intercomparison exercise.

The two stations are operated by KIT and are part of the EUMETSAT's Satellite Application Facility on Land Surface Analysis (LSA SAF). Evora station is in the temperate Mediterranean climate, with a land cover of cork-oak trees and grass. Gobabeb station is in the arid Namibian desert climate and is located on a flat and homogeneous gravel plain (Göttsche et al., 2013).

The core instruments of the two stations are selfcalibrating, chopped radiometers (Heitronics KT15.85 IIP, 9.6-11.5 $\mu \mathrm{m}$ ) which measure the radiation from the relevant

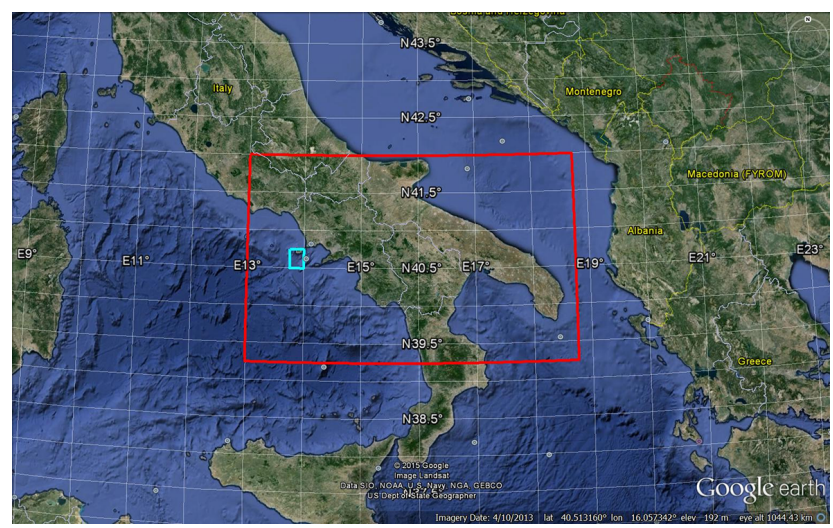

Figure 3. Southern Italy region (boxed area) considered for the case study over sea surface. The cyan box is the SEVIRI pixel used to compare the retrieved $T_{\mathrm{S}}$ against AVHRR data.

components, e.g. grass, soil, tree, shadow, and sky once per minute (see Göttsche and Hulley, 2013, and Theocharous et al., 2010). In the case of Evora station, where local temperature measurements of sunlit/shaded ground and tree canopy may present significant differences, the pixel "in situ" temperature is reconstructed using fixed land cover fractions obtained by classifying high-resolution satellite data (IKONOS), which then served to weigh the radiometric measurements of the endmembers (tree $32 \%$, background $68 \%$ ). We also note that the newest approach (not available for the year 2010) uses dynamic cover fractions from a geometric model (e.g. Ermida et al., 2014).

As mentioned above, the in situ observations of surface temperature refers to the whole year of 2010. The data record is nearly continuous, although there can be data voids due to weather conditions or instrument maintenance.

For the two stations we also have available the SEVIRI LSA SAF surface temperature derived with the algorithm developed by Trigo et al. (2008a) and Freitas et al. (2010).

\subsubsection{Regional case study}

This case study has been set up to check possible spatial biases and the stability of the scheme when processing time series of radiance data points of long time period extent, e.g. 1 year. SEVIRI infrared radiances are recorded and available every $15 \mathrm{~min}$. However, cloudy radiances, if detected, can be skipped during the KF run, and therefore the actual processed SEVIRI radiance record could be made of data points which do not correspond to equally spaced times. In principle, cloud fields can produce large data voids, which could be detrimental to KF stability because the radiance data record is lacking time contiguity and continuity.

With this in mind, an additional case study has been set up, for which we have acquired SEVIRI data for the whole year of 2013. The target area include a relatively large region (both ocean and land) of southern Italy (see Fig. 3). 
For the purpose of comparison, MODIS sea skin temperature and AVHRR sea surface temperature retrievals were acquired for the same period and location. The level 2 MODIS data products are produced and distributed by NASA Goddard Space Flight Center's Ocean Data Processing System (ODPS). The data are available from the website http: //oceandata.sci.gsfc.nasa.gov. Both the AQUA and TERRA satellites have been used. The MODIS product used in the present study is MOD28 Sea Surface Temperature 5-Min L2 Swath $1 \mathrm{~km}$.

The AVHRR data are not direct satellite observations. In fact, these data are better referred to as AVHRR OI (optimal interpolation) SST (sea surface temperature) analysis (Reynolds et al., 2007), because they are the results of an optimal interpolation scheme which combines AVHRR, buoy and ship data to form daily averages. The data are available at the website ftp://eclipse.ncdc.noaa.gov/pub/OI-daily-v2/ $\mathrm{NetCDF} /$ and they are provided on a regular grid of $0.25^{\circ} \times$ $0.25^{\circ}$.

For the whole target area shown in Fig. 3, we have also acquired ECMWF analysis products for the sea skin temperature at the canonical hours 0:00, 6:00, 12:00 and 18:00 UTC. ECMWF model data points are provided on a $0.125^{\circ} \times$ $0.125^{\circ}$ regular grid. They have been space-collocated just by overlapping the SEVIRI spatial grid to that of ECMWF (see, for example, Masiello et al. (2013b). Once the space collocation has been performed, the ECMWF $T_{\mathrm{S}}$ corresponding to a given SEVIRI observation, recorded at time $t$, is obtained through a simple linear interpolation using the ECMWF $T_{\mathrm{s}}$ values at the canonical hours.

\subsubsection{Full-disk case study}

For the purpose of checking the feasibility of the scheme to run at the global scale we have defined a full-disk case study for the month of November 2007.

The area of the full disk covered corresponds to VZA $\leq$ $70^{\circ}$ (see Fig. 1) and consists of 9046159 pixels, of which 3581915 are over land and 5464244 over sea surface.

\subsection{Ancillary data: emissivity}

The application of the KF approach relies on proper a priori information about emissivity. This is needed to properly build up the background, state vector and related covariance matrix, which are used within the KF retrieval approach.

For land surface, emissivity is derived from the University of Wisconsin Baseline Fit Global Infrared Land Surface Emissivity Database (UW/BFEMIS database, e.g. http: //cimss.ssec.wisc.edu/iremis/) (Seemann et al., 2007). The database has a spatial resolution of $0.05^{\circ}$ and a time step of 1 month, which is enough to include the expected seasonality of surface emissivity. UW/BFEMIS covers the years 2003-2013; therefore it is also capable of providing time and spectral cross-correlation among channel emissivities.
The UW/BFEMIS database has been re-mapped to the SEVIRI channels and spatial grid mesh and then used to define a background for the channel emissivity (state vector and its covariance) which depends on time (monthly resolution) and geographic location (SEVIRI pixel resolution). The remapping involves a high-spectral-resolution algorithm which is first applied to the 10-hinge-point UW/BFEMIS emissivities to generate the emissivity spectrum, which, in turn, is convolved with he SEVIRI spectral response. Details of this procedure can be found in Masiello et al. (2013b, 2014). In passing, we note that the algorithm to transform UW/BFEMIS emissivities to high spectral resolution was first proposed and developed by Borbas and Ruston (2010).

For sea surface, the emissivity is defined and derived according to Masuda's emissivity model Masuda et al. (1988). We have developed a look-up table with sea surface emissivity over the spectral range 500 to $3000 \mathrm{~cm}^{-1}$ and a spectral resolution of $0.25 \mathrm{~cm}^{-1}$. The emissivity has been calculated for view angles (vertical zenith angle) ranging from 0 to $89^{\circ}$ (step size of $1^{\circ}$ ) and wind speed from 0 to $15 \mathrm{~m} \mathrm{~s}^{-1}$ (step size $1 \mathrm{~m} \mathrm{~s}^{-1}$ ). For a given VZA, the emissivity state vector is calculated for an average wind speed of $5 \mathrm{~m} \mathrm{~s}^{-1}$, whereas the values corresponding to the other wind speeds are used to derive the background covariance. The high-spectral-resolution emissivity is convolved with the SEVIRI instrumental spectral response function (ISRF) to yield the SEVIRI channel emissivities.

\subsection{Ancillary data: ECMWF analysis}

The ECMWF analysis, at the four canonical hours, for the atmosphere and surface is used to initialize the KF and to provide information for the atmospheric state vector; temperature profile, $T$; water vapour mixing ratio profile, $Q$; and ozone mixing ratio profile, $O$. The surface and atmospheric parameters are directly downloaded from the ECMWF MARS (Meteorological Archival and Retrieval System) archive and consist of surface temperature and pressure, profiles of temperature, water vapour and ozone. The analysis is available on a horizontal grid mesh of $0.125^{\circ} \times 0.125^{\circ}$. The atmospheric profiles are obtained on either 91 pressure levels (until 25 July 2013) or 137 pressure levels (from 26 June 2013). ECMWF analysis is linearly interpolated to the SEVIRI time-space grid mesh before it is used to initialize the KF. The procedure is the same as that used for the surface temperature (see end of Sect. 2.1.2).

\section{Methodology: implementation of the Kalman filter for $\left(T_{\mathrm{s}}, \epsilon\right)$}

The basic KF implementation performs a simultaneous mathematical inversion of the radiative transfer equation for $\left(T_{\mathrm{s}}, \epsilon\right)$. The retrieval algorithm has been developed in such a way as to provide a suitable prototype for use at a satellite data processing centre for a range of applications involving 
remote sensing of the surface. In fact, the system can ingest SEVIRI data and ancillary MARS/ECMWF analyses in their native format. For the sake of clarity, here we limit ourselves to showing the KF basic equations which apply to the $\left(T_{\mathrm{S}}, \epsilon\right)$ retrieval problem.

The retrieved state vector, $\boldsymbol{v}$, is made up of $m(m=8)$ SEVIRI infrared channel emissivities and the surface temperature,

$\boldsymbol{v}=\left(e_{1}, e_{2}, \ldots, e_{m}, T_{\mathrm{S}}\right)^{T}$,

where the superscript $T$ stands for transpose and $e$ is the logit-transformed emissivity

$e=\log \frac{\epsilon}{1-\epsilon}$.

The logit transform ensures that the we deal with emissivity correctly constrained in its physical variability range of 0 1 . The transform has been successfully used with emissivity retrieval for IASI (Masiello and Serio, 2013; Masiello et al., 2014) and SEVIRI (Masiello et al., 2013b).

In principle the scheme can be applied to the $m=8$ infrared channels of the SEVIRI imager, which are listed in Table 1 . However, effective results are expected for the three atmospheric window channels (7, 9 and 10) which are less sensitive to atmospheric parameters, namely temperature, water vapour and ozone. For the shortwave window channel at $3.9 \mu \mathrm{m}$, retrieval is only recommended at night-time to avoid solar contamination.

In the following, to simplify the exposition we will assume that the times are indexed by integers, $t=1,2, \ldots$, although handling unequally spaced times does not add any fundamental difficulty. With this in mind, the non-linear KF estimate or analysis, $\hat{\boldsymbol{v}}_{\boldsymbol{t}}$ of $\boldsymbol{v}_{t}$, at a generic time $t$ is given by (e.g. Nychka and Anderson, 2010)

$\hat{\boldsymbol{x}}_{t}=\boldsymbol{x}_{t a}+\left(\mathbf{K}_{t}^{T} \mathbf{S}_{\varepsilon}^{-1} \mathbf{K}_{t}+\mathbf{S}_{a}\right)^{-1} \mathbf{K}_{t}^{T} \mathbf{S}_{\varepsilon}^{-1}\left(\boldsymbol{y}_{t}-\mathbf{K}_{t} \boldsymbol{x}_{t a}\right)$,

where we have posed

$$
\left\{\begin{array}{cc}
\hat{\boldsymbol{x}}_{t} & =\hat{\boldsymbol{v}}_{t}-\boldsymbol{v}_{t ; \mathrm{fg}} \\
\boldsymbol{y}_{t} & =\boldsymbol{R}_{t}-F\left(\boldsymbol{v}_{t ; \mathrm{fg}}\right) \\
\boldsymbol{x}_{t a} & =\mathbf{v}_{t a}-\boldsymbol{v}_{t ; \mathrm{fg}}
\end{array}\right.
$$

and where the subscripts $a$ and $f g$ indicate background and first-guess parameters, respectively, at time $t$. $\boldsymbol{R}$ is the radiance vector and $F$ is the forward model.

Again, with reference to Eqs. (9) and (3), $\mathbf{K}_{t}$ is the Jacobian at time $t$,

$$
\mathbf{K}_{t}=\left(\frac{\partial F}{\partial \boldsymbol{v}}\right)_{\boldsymbol{v}=\boldsymbol{v}_{t ; \mathrm{fg}}} .
$$

The a posteriori covariance of the estimate Eq. (3) is given by

$\hat{\boldsymbol{S}}_{t}=\left(\mathbf{K}_{t}^{T} \mathbf{S}_{\varepsilon}^{-1} \mathbf{K}_{t}+\mathbf{S}_{a}\right)^{-1}$.
The analysis is propagated forward to time $t+1$ to obtain the forecast according to

$\hat{\boldsymbol{v}}_{t+1}^{f}=\mathbf{M} \hat{\boldsymbol{v}}_{t}$

which has covariance given by

$\hat{\boldsymbol{S}}_{t+1}^{f}=\mathbf{M} \hat{\boldsymbol{S}}_{t} \mathbf{M}^{T}+\mathbf{S}_{\eta}$.

The dynamical model operator, $\mathbf{M}$, is assumed to be the identity matrix (Masiello et al., 2013b). In this way, the retrieval scheme assumes a persistence model for both temperature and emissivity. To complete the description of the scheme, the covariance matrices $\mathbf{S}_{\varepsilon}, \mathbf{S}_{a}$, and $\mathbf{S}_{\eta}$ are the observational covariance matrix, the background covariance matrix and the stochastic term covariance matrix.

KF operates sequentially, which means that the updated analysis at a given time $t+1$ is based on the new observations at time $t+1$ and the state vector estimate at the previous time $t$, which in our case (because $\mathbf{M}$ is the identity) is identified with the forecast (see Eq. 7). Update and forecast steps are repeated as time advances and new observations arrive.

It can be shown (e.g. Nychka and Anderson, 2010) that the analysis (Eq. 3) is the minimizer of the linearized quadratic form or cost function $S$ given by

$$
\begin{aligned}
S= & \min _{x} \frac{1}{2}\left(\boldsymbol{y}_{t}-\mathbf{K}_{t} \boldsymbol{x}_{t}\right)^{T} \mathbf{S}_{\varepsilon}^{-1}\left(\boldsymbol{y}_{t}-\mathbf{K}_{t} \boldsymbol{x}_{t}\right)+ \\
& \frac{1}{2}\left(\boldsymbol{x}_{t}-\boldsymbol{x}_{t a}\right)^{T} \mathbf{S}_{a}^{-1}\left(\boldsymbol{x}_{t}-\boldsymbol{x}_{t a}\right),
\end{aligned}
$$

which states that the KF Eqs. (3) and (6) are the same as the equations of optimal estimation (Rodgers, 2000). Optimal Estimation can be regarded as a particular case of KF. (e.g. Nychka and Anderson, 2010).

In passing, we also note here that the retrieval scheme above is non-linear because at each time $t$ we have to linearize the forward model and iterate the solution until the cost function (see Eq. 9) is reduced below a given threshold (e.g. Masiello et al., 2013b). Under linearity, the value of twice the quadratic $S$ (Eq. 9) at the minimum is distributed as a $\chi^{2}$ variable with $m$ degrees of freedom (Tarantola, 1987). A $\chi^{2}$ threshold, $\chi_{\mathrm{th}}^{2}$ at the $3 \sigma$ confidence interval, is given by $\chi_{\mathrm{th}}^{2}=m+3 \sqrt{2 m}$ : therefore the iterative procedure is stopped when

$\chi^{2}=2 \times S \leq \chi_{\mathrm{th}}^{2}$.

Linearization of the forward model is done around a firstguess state vector, which can depend on time and should not be confused with the background or analysis. Because of the linearization and iteration steps the scheme is non-linear. Non-linear KF schemes are normally referred to as extended KF. However, for the sake of brevity, we will continue to refer to the scheme above as KF. 


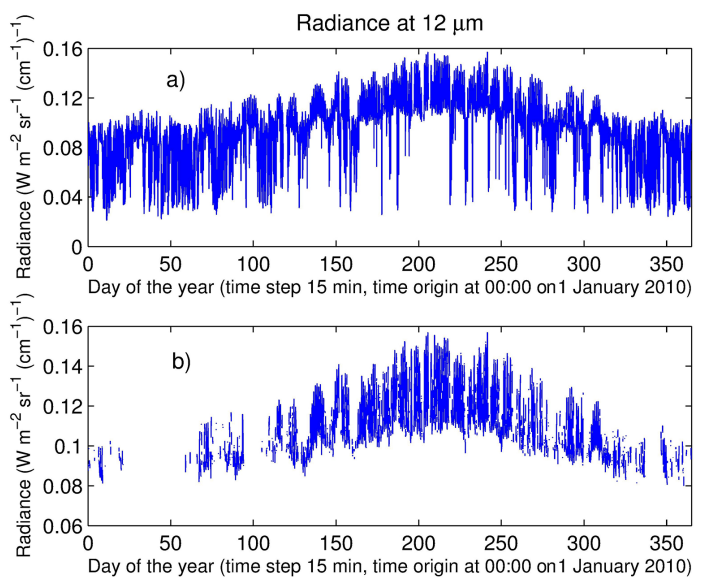

Figure 4. Yearly SEVIRI $12 \mu \mathrm{m}$ channel data record for the validation station of Evora: (a) original radiance data record and (b) after removing cloudy radiances.

\subsection{KF parameter settings}

An important aspect of a given KF implementation is the setting of the many parameters involved within the retrieval scheme. The settings of the main parameters is here summarized for the benefit of the reader. An in-depth assessment and analysis of the sensitivity of the retrieval to these parameters can be found in Serio et al. (2014), whereas an analysis of the sensitivity to the state operator $\mathbf{M}$ and implications by setting it to the identity operator are analysed and discussed in Serio et al. (2013) and (Masiello et al., 2013b).

To begin with, we clarify that $\mathbf{S}_{\varepsilon}$ is a static parameter and is set equal to the SEVIRI radiometric noise.

The covariance operator $\mathbf{S}_{a}$ has to be initialized at time $t=0$. At time $t=0$, the matrix $\mathbf{S}_{a}$ does not consider crosscorrelation between emissivity and surface temperature - that is, it is of the form

$$
\left(\begin{array}{cc}
\mathbf{S}_{a \epsilon ; 0}, & 0 \\
0, & \sigma_{T_{\mathrm{s}} ; 0}^{2}
\end{array}\right),
$$

where $\mathbf{S}_{a \epsilon ; 0}$ is the uncertainty associated with the emissivity vector and $\sigma_{T_{\mathrm{s}} ; 0}^{2}$ is the uncertainty associated with the surface temperature. For emissivity, as already mentioned, $\mathbf{S}_{a \epsilon ; 0}$ is obtained from the UW/BFEMIS database (land) or the Masuda's emissivity model (sea surface). The initial value $\sigma_{T_{\mathrm{s}} ; 0}^{2}=1 \mathrm{~K}^{2}$ is used for the surface temperature of either land or ocean. According to Wikle and Berliner (2007), these uncertainties do not need to be accurately prescribed at $t=0$ because at a later time $\mathbf{S}_{a}$ evolves according to Eq. 8 - that is, it is identified with the forecast covariance. We note that at later time $\mathbf{S}_{a}$ may also include cross-correlation between $T_{\mathrm{S}}$ and $\epsilon$.

Another important parameter is the matrix $\mathbf{S}_{\eta}$, because it trades off between a retrieval dominated by either the dynamical model (a persistence equation in our implementation) or the observations.
$\mathbf{S}_{\eta}$ is the covariance of the stochastic term, and in our implementation it is a static parameter (not evolved with time). It takes the form

$\mathbf{S}_{\eta}=\left(\begin{array}{cc}f^{-2} \mathbf{S}_{a \epsilon ; 0}, & 0 \\ 0, & \sigma_{T_{s} ; \eta}^{2}\end{array}\right)$,

where $f$ and $\sigma_{T_{\mathrm{s}} ; \eta}^{2}$ are two tuning parameters. For the work shown here, we use for land $f=5$ and $\sigma_{T_{\mathrm{s}} ; \eta}^{2}=1 \mathrm{~K}^{2}$, whereas for sea surface we have $f=5$ and $\sigma_{T_{\mathrm{s}} ; \eta}^{2}=0.1 \mathrm{~K}^{2}$.

\subsection{The forward model}

One of the key aspects of the KF scheme is the use of a physical forward model which solves the radiative transfer equation in the form needed for the present application. The forward model implemented with the baseline version of KF is the so-called $\sigma$-SEVIRI code (Masiello et al., 2013b). Also, for potential applications to hyper-spectral sounders, $\sigma$-SEVIRI has been designed as a monochromatic forward model, based on a look-up table for the optical depth. The sampling along the wave number axis used to develop and implement the look-up table has been optimized for SEVIRI (e.g. Masiello et al., 2013b). Furthermore, the forward model can deal with Lambertian and specular reflecting surfaces. Again, this is an important aspect when dealing with the emissivity retrieval of land and ocean emissivity. To date, considering the SEVIRI instrument, this capability of running in the infrared wave number range with a Lambertian model is unique to $\sigma$-SEVIRI.

The code $\sigma$-SEVIRI computes analytical Jacobian derivatives for any state vector parameter. Spectral monochromatic radiance and Jacobians are reduced to the SEVIRI spectral resolution through convolution with the SEVIRI ISRF.

The code $\sigma$-SEVIRI is a legacy of $\sigma$-IASI (Amato et al., 2002; Carissimo et al., 2005), a radiative transfer model developed for IASI. Over the past year, the model $\sigma$-IASI has been largely validated with aircraft and satellite high spectral infrared observations (e.g. Wulfmeyer et al., 2005; Grieco et al., 2007; Masiello et al., 2009, 2013a).

\section{Results: validation and comparison to similar satellite-derived products}

This section is devoted to the presentation and discussion of the case studies we have defined in order to check the retrieval performance and stability of the KF approach.

Before presenting the results, we remark that SEVIRI radiances are processed at their higher rate of $15 \mathrm{~min}$. However, in the case of detected cloudiness, radiances are skipped and, therefore, the time lag between two consecutive observations may become several hours or even days. This is exemplified in Fig. 4, which shows the yearly data record for the Evora station corresponding to the SEVIRI channel at $12 \mu \mathrm{m}$. Once the original, cloudy data set has been screened for clouds, we 

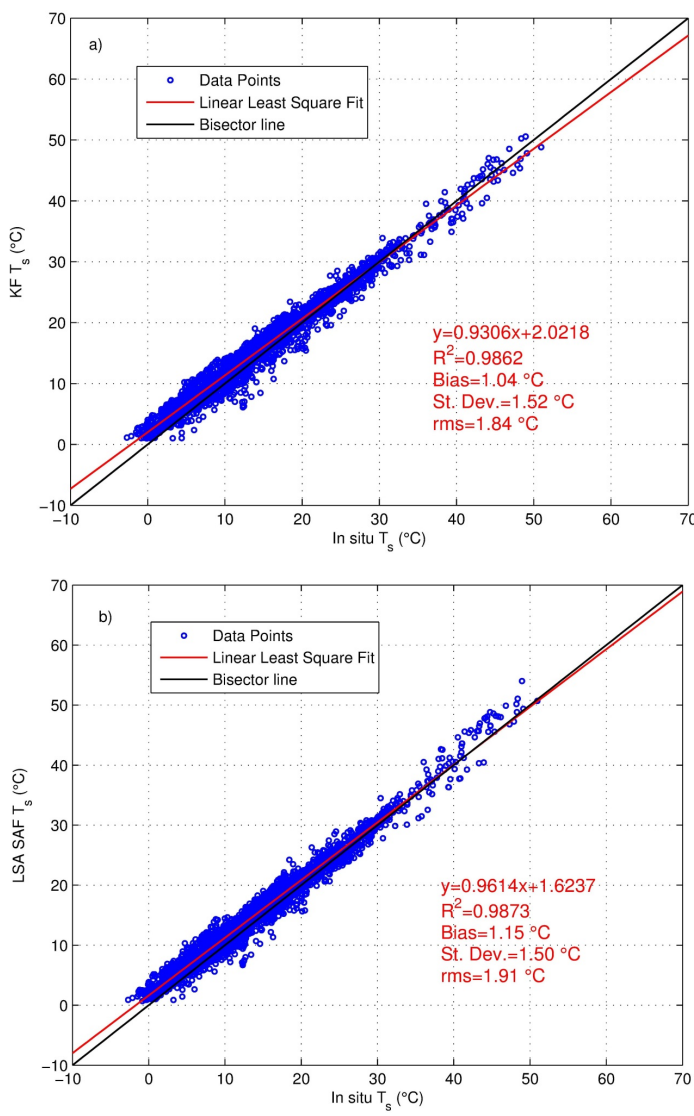

Figure 5. Evora station. Scatter plot of SEVIRI surface temperature retrieval and in situ observations at Evora for 2010 (a) KF (this study retrieval) and (b) LSA SAF retrieval. Note: $R^{2}$ is the linear correlation coefficient.

are left with a data record sampled at unequally times. It can be seen from Fig. 4 that in wintertime (especially in February) the time lag between two consecutive data points can be as large as several days.

Thus, in the case of large data voids we could experience a lack of continuity and the problem of whether this lack of continuity could affect the stability of the algorithm arises. As mentioned above, the assessment of this stability is one of the main objective of the present paper and will be discussed in the following of this section on the basis of the various case studies we have set up.

To begin with, we discuss the results for the two in situ validation stations.

\subsection{Evora station}

Figure 5a shows a scatter plot of the SEVIRI KF retrieval against the in situ measurements of $T_{\mathrm{s}}$, whereas Fig. $5 \mathrm{~b}$ provides the same comparison, but now of in situ $T_{\mathrm{S}}$ with the SEVIRI LSA SAF surface temperature. The comparison is performed only for retrievals which reached convergence according to the cost function criterion (see Eq. 10). The yearly

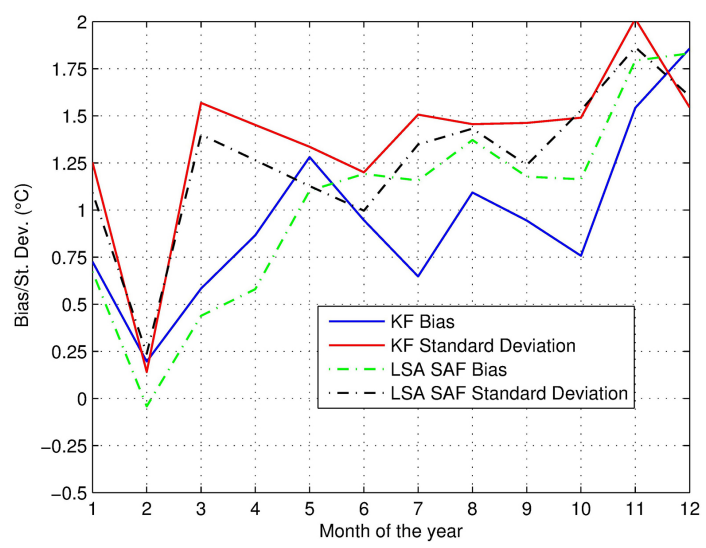

Figure 6. Evora station, year 2010. Monthly mean surface temperature difference (SEVIRI-in situ) and related SD. The low values in February are due to few data points being available for this month.

root mean square (rms) difference of retrievals and situ $T_{\mathrm{S}}$ is $1.84{ }^{\circ} \mathrm{C}$ for $\mathrm{KF}$ and $1.91^{\circ} \mathrm{C}$ for LSA SAF. The yearly bias is $1.04^{\circ} \mathrm{C}$ for $\mathrm{KF}$ against $1.15^{\circ} \mathrm{C}$, showing that the $\mathrm{KF}$ is slightly superior to LSA SAF. This is also confirmed from Fig. 6, which shows the monthly mean (bias) and standard deviation (SD) of the difference (KF-in situ) and (LSA SAFin situ). In this figure the low values corresponding to February are not statistically significant because of the very few data points for this month (e.g. see Fig. 4). For this month only three SEVIRI data points were available because of persistent cloud coverage. For the other months the number of data points is normally above 100 . We stress again that the number of retrievals for each months is ultimately determined by the cost function criterion (see Eq. 10).

Apart from February, we see that the bias oscillates around $1{ }^{\circ} \mathrm{C}$ and KF performs better than LSA SAF during the summer season. Also, from the scatter plots of Fig. 5, we see that, compared to KF, the LSA SAF bias is slightly larger at higher temperatures. This is better seen from Fig. 7 which shows a short sequence in July 2010 of retrievals, in situ observations and the corresponding differences. It is seen from Fig. 7 that LSA SAF has larger bias than KF when the maximum temperature is reached. Figure 7 also exemplifies the stability of the KF in the case of large data voids. A large data void occurs in between the Julian days 218 and 220. Yet, the retrieved surface temperature shows a stable behaviour and no important bias is seen at the gap end points.

It should also be stressed that Evora station does not have an homogeneous land type and coverage within the SEVIRI pixel. In situ observations are obtained by merging together the radiant temperatures from the various components of the composite scene. This inhomogeneity can explain some large temperature differences (e.g. Fig. 7). Normally the larger fluctuations appear at sunrise (which corresponds to the minimum temperature), when the shadowing effects may change quickly (Guillevic et al., 2013; Ermida et al., 2014). Because 

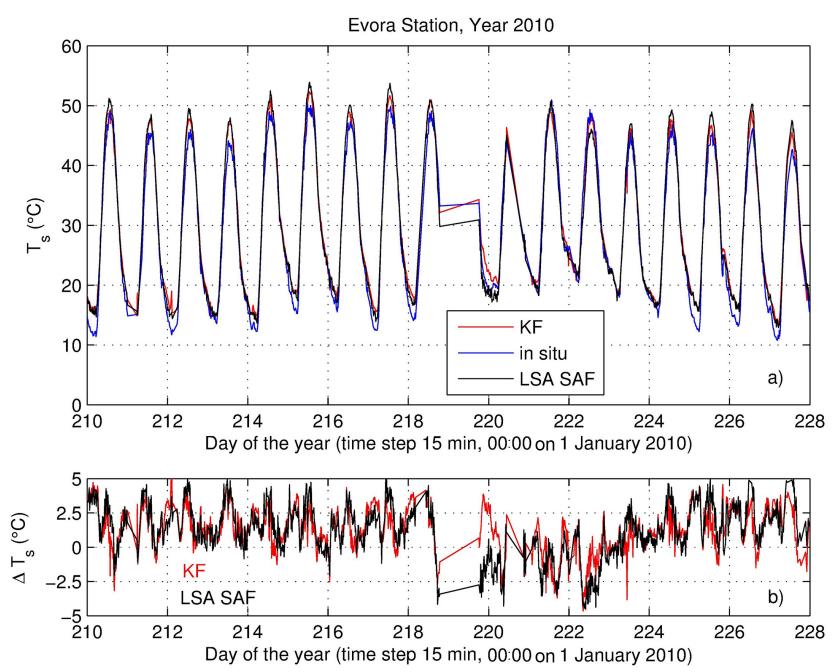

Figure 7. Evora station. (a) Example of $T_{\mathrm{S}}$ time series for a few days in July 2010. (b) Difference (KF-in situ) and (LSA SAF-in situ).

of this difficulty, the same accuracy of in situ data remains a problem and we cannot really say which algorithm (KF or LSA SAF ) performs better for $T_{\mathrm{s}}$. However, when comparing KF to LSA SAF, it should be stressed that, unlike LSA SAF, KF simultaneously retrieves emissivity along with temperature.

Figure 8 shows the time sequence of the retrieval for emissivity. The retrieval has been smoothed with a movingaverage filter with a time window of $3 \mathrm{~h}$ in order to suppress spurious values due to undetected cloudy radiances. Nevertheless, small-scale, random fluctuations are still visible. In fact, these fluctuations can be further reduced if we smooth the 15 min emissivity retrieval with a moving-average filter with a time window of 1 day. The result is once again shown in Fig. 8. It is important to note that the emissivity retrieval is stable and is not affected by the large data voids occurring during winter times.

To further intercompare the emissivity at different channels, the 1-day smoothed emissivities are plotted together in Fig. 9. It can be seen that the retrieval is sensitive to the vegetation seasonal cycle. In fact, in summer the emissivity at $8.7 \mu \mathrm{m}$ is definitely larger than that at 10.8 and $12 \mu \mathrm{m}$, whereas the three are comparable in winter. This phenomenon is in agreement with the different emissivity of green (winter-spring) and dry (summer) grass (e.g. Baldridge et al., 2009). Green grass has an emissivity which is almost constant over the spectral range $8-12 \mu \mathrm{m}$, whereas that of dry grass at $8.7 \mu \mathrm{m}$ is significantly larger than that at 10.8 and $12 \mu \mathrm{m}$. This green-dry grass emissivity contrast has been used for land cover classification (e.g. French et al., 2000).

The emissivity at $10.8 \mu \mathrm{m}$ is $\approx 0.97$ in May and $\approx 0.965$ in October. For comparison, the $10.8 \mu \mathrm{m}$ emissivity deter-
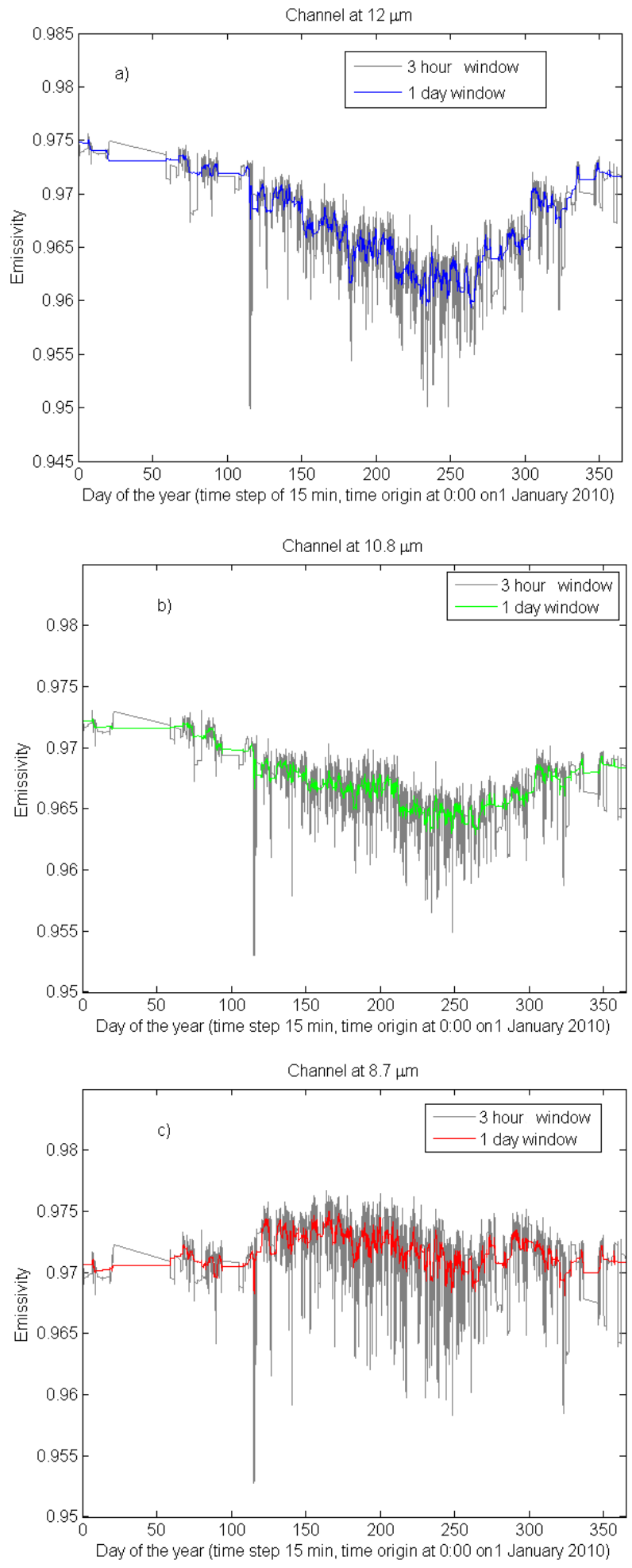

Figure 8. Emissivity retrieval for the Evora validation station. The retrieval has been smoothed with a moving-average filter with time windows of $3 \mathrm{~h}$ and 1 day. Top panel, $12 \mu \mathrm{m}$; middle panel, $10.8 \mu \mathrm{m}$; bottom panel, $8.7 \mu \mathrm{m}$. Retrievals refer to the year 2010 . 


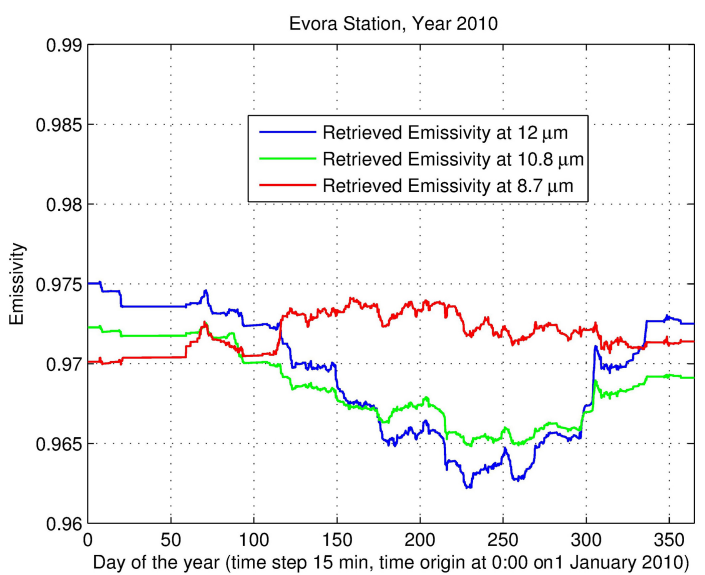

Figure 9. Comparing the emissivity retrieval for the Evora station at the three window channels. The retrieval has been smoothed with a moving-average filter with a time window of 1 day. Retrievals refer to the year 2010 .
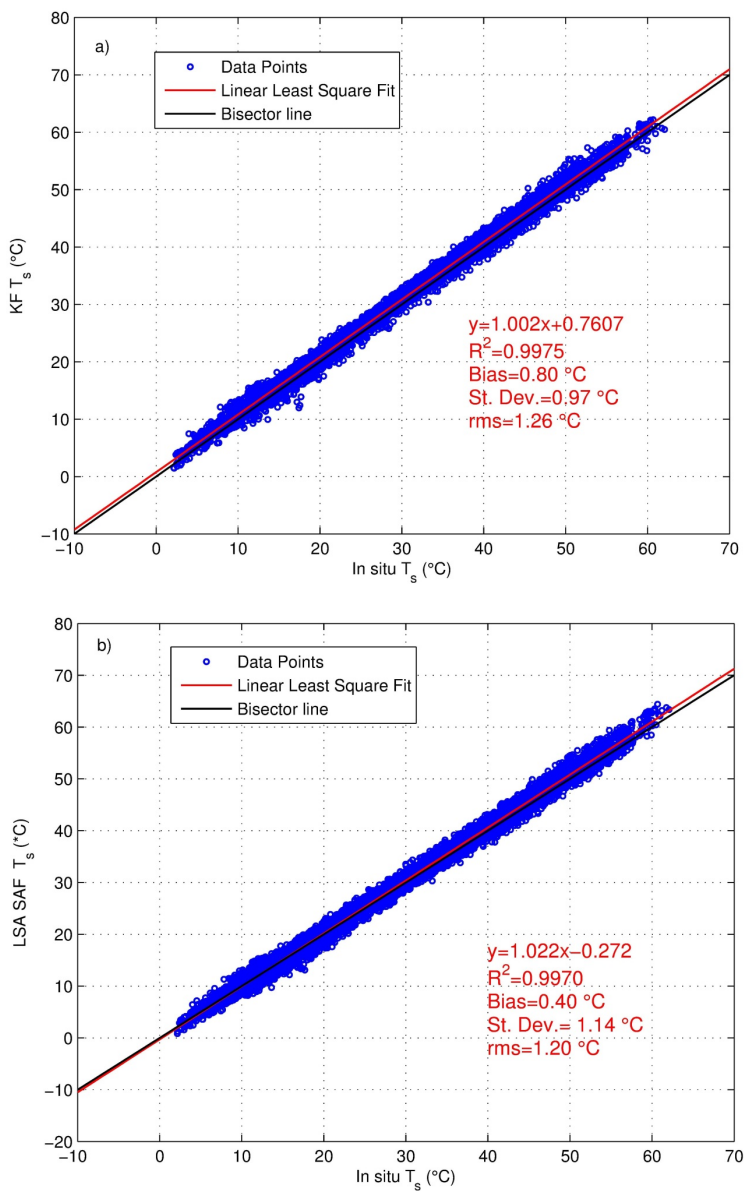

Figure 10. Scatterplot of SEVIRI surface temperature retrieval and in situ observations at Gobabeb for 2010. (a) KF (this study retrieval) and (b) LSA SAF retrieval. Note: $R^{2}$ is the linear correlation coefficient.

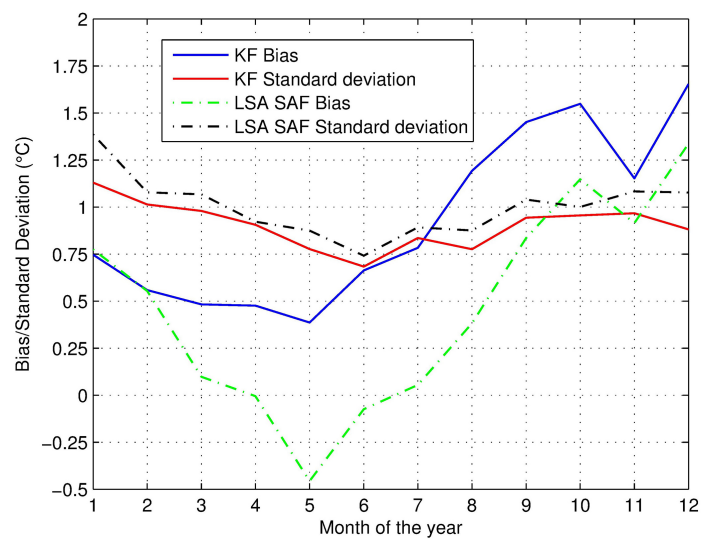

Figure 11. Gobabeb station, year 2010. Monthly mean surface temperature difference (SEVIRI-in situ) and related SD.

mined for 2009 by LSA SAF varies between 0.987 in May and 0.974 in October, while the corresponding UW/BFEMIS emissivity varies between 0.982 in May and 0.960 in October (Xu et al., 2014).

\subsection{Gobabeb station}

Gobabeb station has been selected mainly for the homogeneous surface coverage, which should simplify the interpretation and comparison of in situ measurements to retrievals (Göttsche et al., 2013).

As done for Evora station, first we show in Fig. 10a the scatter plot of the KF estimated surface temperature against in situ observations, whereas Fig. 10b compares in situ with SEVIRI LSA SAF. Once again, the comparison is performed only for the retrievals which reached convergence according to the cost function criterion. If we compare with Fig. 5 (corresponding to Evora station), the yearly rms difference for the case of $\mathrm{KF}$ is $1.26^{\circ} \mathrm{C}$, which is slightly larger than the corresponding LSA SAF, which is $1.20^{\circ} \mathrm{C}$.

Both KF and LSA SAF are in excellent agreement with the in situ observations. The comparison between LSA SAF and KF suggests that the former performs slightly better than the latter: the yearly bias is greater for $\mathrm{KF}\left(\approx 0.80^{\circ} \mathrm{C}\right)$ than for LSA SAF $\left(\approx 0.40^{\circ} \mathrm{C}\right)$. The situation is reversed for the $\mathrm{SD}$, namely $\approx 0.97^{\circ} \mathrm{C}(\mathrm{KF})$ vs. $\approx 1.14^{\circ} \mathrm{C}(\mathrm{LSA} \mathrm{SAF})$. However, a closer look at the results shows a sort of seasonal compensation for the case of LSA SAF. The bias compensation is visible in Fig. 10 and is more clearly seen from Fig. 11, which shows the monthly mean and SD of the difference SEVIRI-in situ for both KF and LSA SAF. It is seen that LSA SAF has a slightly seasonal bias which becomes negative in May, whereas KF shows a more uniform behaviour.

Figure 12 shows the time sequence of the retrieval for emissivity. The time resolution of the retrieval is $15 \mathrm{~min}$ (a moving-average smoothing was applied with a window width of $3 \mathrm{~h}$ ). There are small-scale (day-night) variations in emissivity, which are most evident for the channel at $8.7 \mu \mathrm{m}$ 


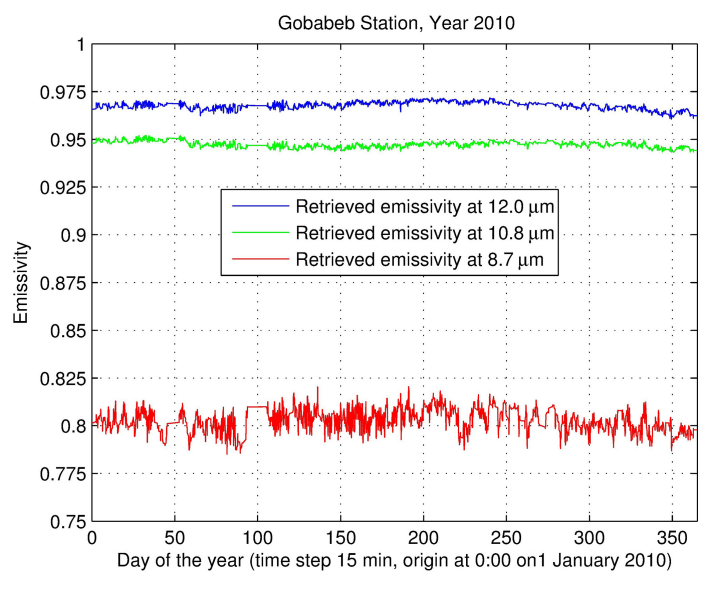

Figure 12. Gobabeb station. Emissivity retrieval. The retrieval has been smoothed with a moving-average filter with a time window of $3 \mathrm{~h}$. Retrievals refer to the year 2010.

because of the strong contrast introduced by quartz absorption (reststrahlen effect). It is likely that these diurnal fluctuations are the result of direct adsorption of water vapour from the atmosphere (e.g. Li et al., 2012). Due to the low emissivities in the so-called reststrahlen bands of (dry) quartz, this effect is most pronounced around $9 \mu \mathrm{m}$ during the dry season, which for Gobabeb coincides with winter. Figure 13 shows a clear-sky sequence of the retrieved pair $\left(T_{\mathrm{s}}, \epsilon\right)$ for 10 days of June 2010. It is seen that the emissivity follows the temperature daily cycle with larger emissivity at night-time (before sunrise), which is consistent with a daily cycle of soil moisture driven by direct water vapour adsorption. The diurnal emissivity variation in SEVIRI channel $8.7 \mu \mathrm{m}$ has a peak-to-peak amplitude $\leq 0.015$, a result which is consistent with the findings shown by $\mathrm{Li}$ et al. (2012). In contrast, the seasonal variation of emissivity is much smaller than for vegetated soil, e.g. compare Fig. 12 and 8).

Also, for Gobabeb, KF was not affected by data voids and the retrieval was stable for $T_{\mathrm{S}}$ and $\epsilon$ (see e.g. Fig. 12).

Finally, it is worth noting that the KF-retrieved emissivity for the $10.8 \mu \mathrm{m}$ channel is in very good agreement with that estimated for the Gobabeb gravel plain with satellite observations (MODIS and ASTER (Advanced Spaceborne Thermal Emission and Reflection Radiometer)) and the in situ box method approach (Göttsche and Hulley, 2013). KF yields an estimation of 0.946 with a variability (SD) of \pm 0.002 , whereas the combination of the various methods and estimates presented in Göttsche and Hulley (2013) gives the value of $0.944 \pm 0.015$. For the year 2009 , the $10.8 \mu \mathrm{m}$ emissivity determined by LSA SAF is quasi-static at 0.948 (Trigo et al., 2008b), while the corresponding UW/BFEMIS emissivity varies between 0.945 and 0.955 (Xu et al., 2014).
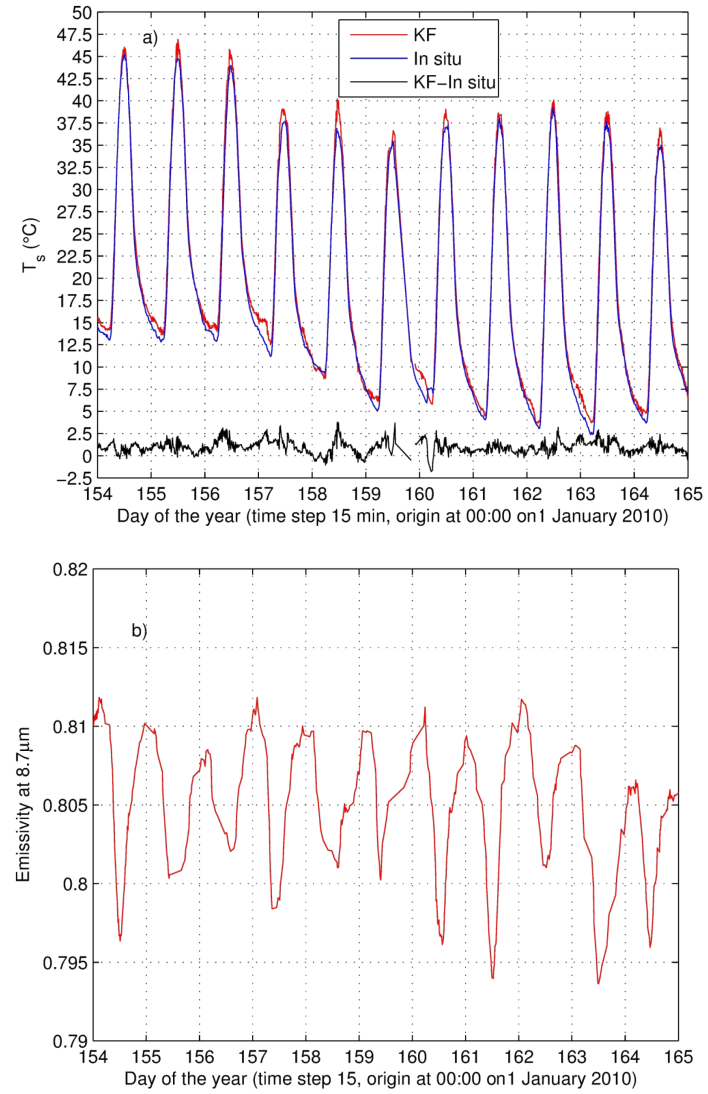

Figure 13. Gobabeb station surface temperature (a) and $8.7 \mu \mathrm{m}$ emissivity (b) retrieval for a clear-sky sequence of days in June 2010. The emissivity retrieval has been smoothed with a movingaverage filter with a time window of $3 \mathrm{~h}$.

\subsection{Regional case study}

In this section we will show the results of the comparison exercise for the case of the southern Italy target area shown in Fig. 3. The comparison will deal with the sea surface, for which we know that both ECMWF and satellite products are highly reliable.

\subsubsection{Comparison with ECMWF products}

The comparison with ECMWF model data for $T_{\mathrm{S}}$ shows a very good agreement with absolute monthly mean differences below $0.4{ }^{\circ} \mathrm{C}$ and $\mathrm{SD}$ around $1{ }^{\circ} \mathrm{C}$. Figure 14 shows the histogram of $T_{\mathrm{S}}$ differences for the whole year 2013. It is seen that the yearly average difference is only $-0.07^{\circ} \mathrm{C}$ with a SD of $1.02{ }^{\circ} \mathrm{C}$. The statistics have been compiled with 2754238 data points. It is worth noting that our findings testify the high reliability reached by the ECMWF sea surface temperature product.

To check for a seasonal systematic error of the retrieval we have computed the monthly averages and SDs of the difference between SEVIRI and ECMWF. These are shown in 

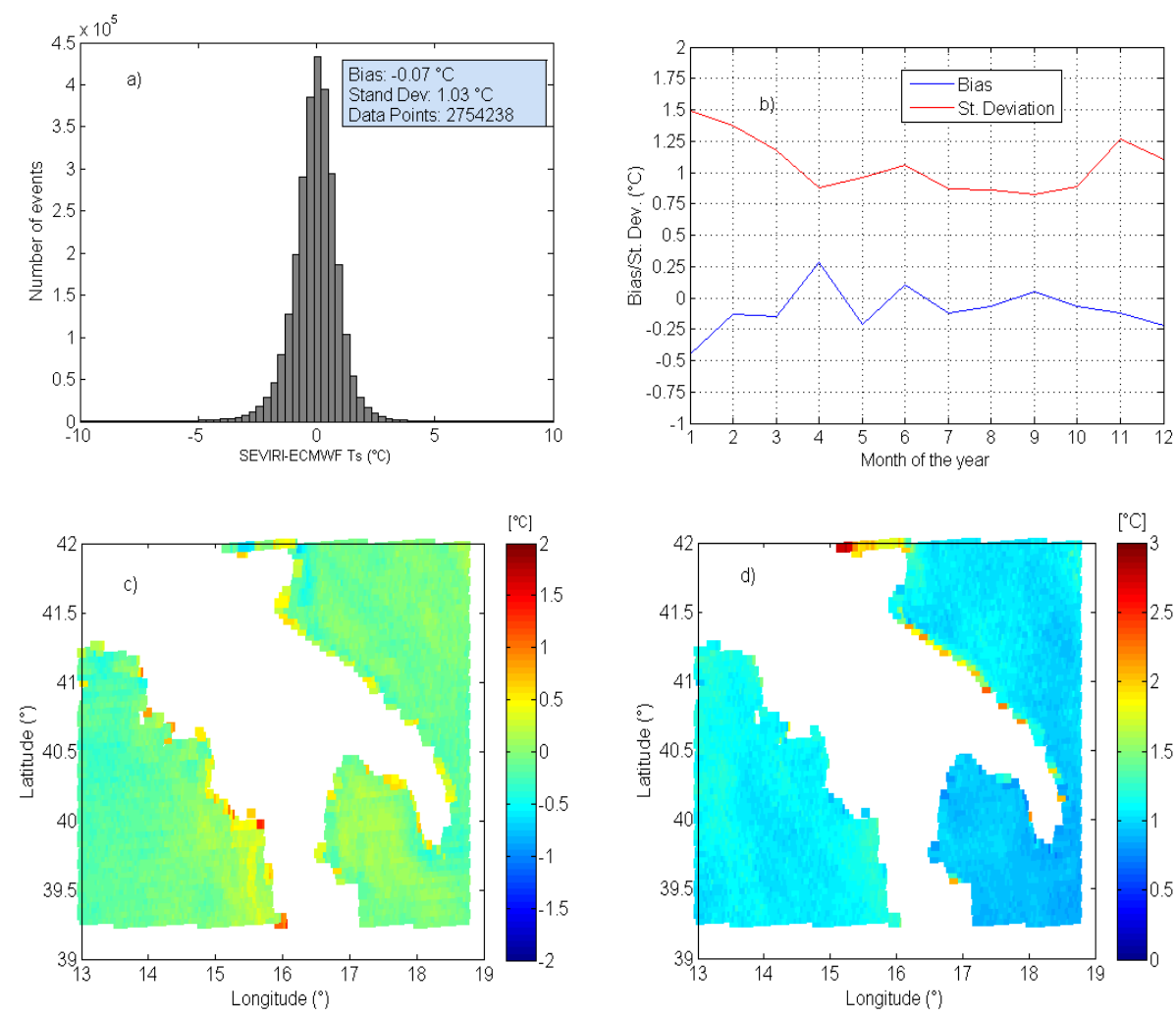

Figure 14. Year 2013. Comparison of SEVIRI-retrieved skin temperature with ECMWF analysis: (a) histogram of the surface temperature difference $\Delta T_{\mathrm{S}}$ (SEVIRI-ECMWF), (b) monthly mean and related SD of $\Delta T_{\mathrm{S}}$, (c) Map of the yearly average surface temperature difference (SEVIRI-ECMWF) and related SD (d).

Fig. 14b. It is seen that the mean difference and SD tend to decrease in the summer season, which is quite understandable because the frequency of cloudiness tends to decrease in summer.

Figure $14 \mathrm{c}$ shows the spatial distribution of the yearly surface temperature differences. It is seen that, apart from SEVIRI pixels close to the coast, the difference is homogeneously zero everywhere. The variability (SD) of the surface temperature difference does not show any important spatial dependence as can be seen from Fig. 14d.

Finally, once again the results shown in this section exemplify the resilience of the KF against data voids due to cloudiness.

\subsubsection{Comparison with sea surface MODIS products}

The comparison has been performed using the SEVIRI retrieval for $T_{\mathrm{S}}$ and the time-space-collocated MODIS products. Also, for this case, the comparison (Fig. 15) suggests a very good agreement with a yearly mean difference of $-0.07^{\circ} \mathrm{C}$ and a SD of $1.05^{\circ} \mathrm{C}$. These two values have been obtained with a total of 3230710 data points. Apart from the month of December 2013, the monthly mean difference is normally $\approx 0.2^{\circ} \mathrm{C}$ or below as can be seen from Fig. $15 \mathrm{~b}$. The anomalous case of December 2013 is likely due to cloud contamination of MODIS overpasses: MODIS has a negative bias of $\approx 0.5{ }^{\circ} \mathrm{C}$ with respect to SEVIRI, which is uniform over the target area. This behaviour is not seen for other months.

Figure $15 \mathrm{c}$ shows the spatial distribution of the yearly surface temperature differences. Once again, it is seen that, apart from SEVIRI pixels close to the coast, the difference is homogeneously zero everywhere. A good spatial homogeneity is also seen for the variability (SD) of the surface temperature difference as can be seen from Fig. 15d.

As for the comparison with the ECMWF fields, the comparison with MODIS also evidences a good stability and reliability of the KF retrieval, despite larger data voids due to clouds.

\subsubsection{Comparison with AVHRR OI SST analysis}

For the case of AVHRR, a comparison has been performed to gain further insights into understanding whether the KF approach is capable of following the seasonal cycle. The AVHRR data we are going to compare with the KF algorithm are not direct AVHRR skin temperature values. Instead, AVHRR data are assimilated within the OI SST scheme, yielding daily values of surface temperature corrected for possible artifacts of the polar orbit (e.g. Reynolds et al., 

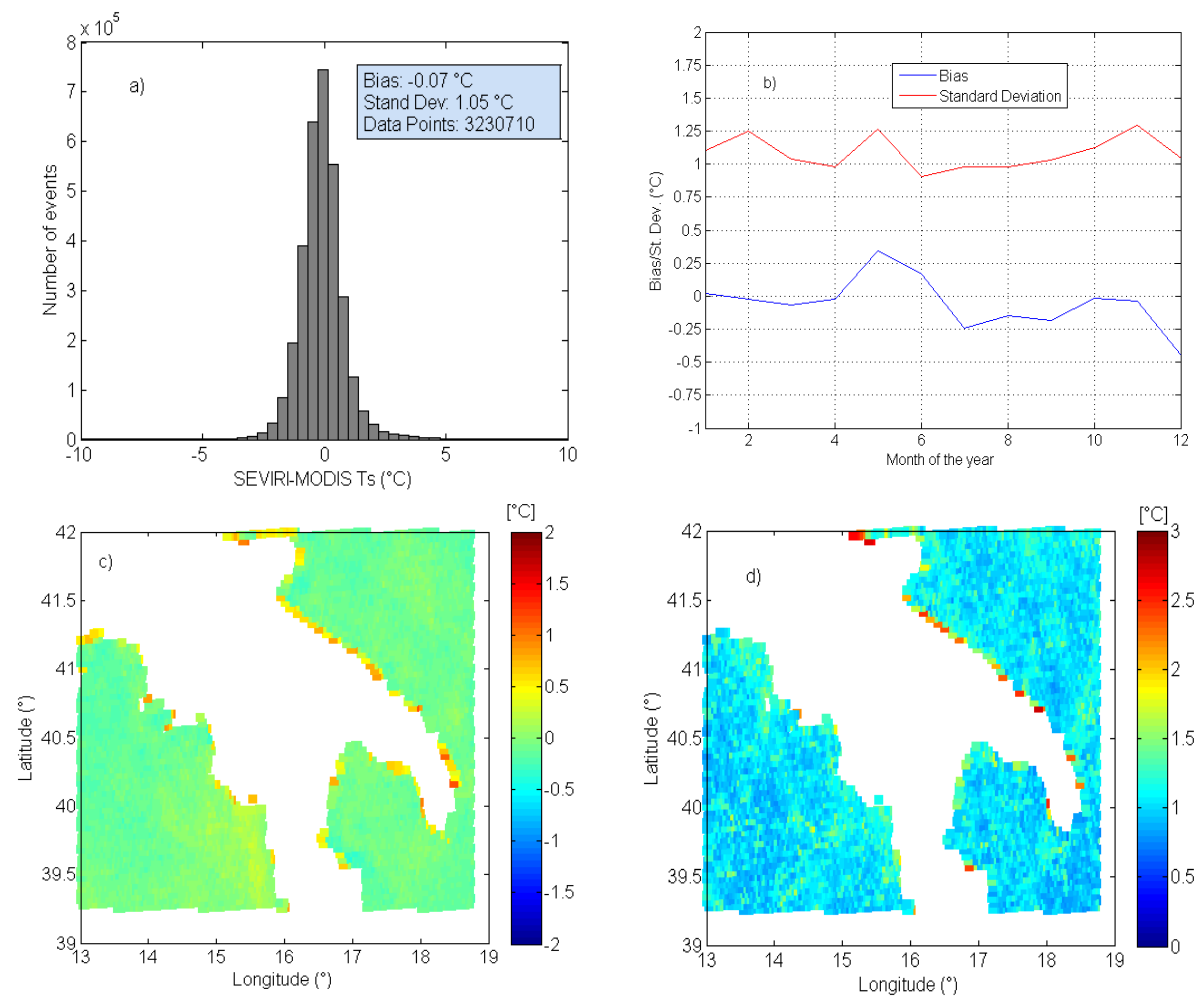

Figure 15. Year 2013. Comparison of SEVIRI-retrieved skin temperature with MODIS: (a) histogram of the surface temperature difference $\Delta T_{\mathrm{S}}$ (SEVIRI-MODIS), (b) monthly mean and related SD of $\Delta T_{\mathrm{S}}$, (c) map of the yearly average surface temperature difference (SEVIRIMODIS) and related SD (d).
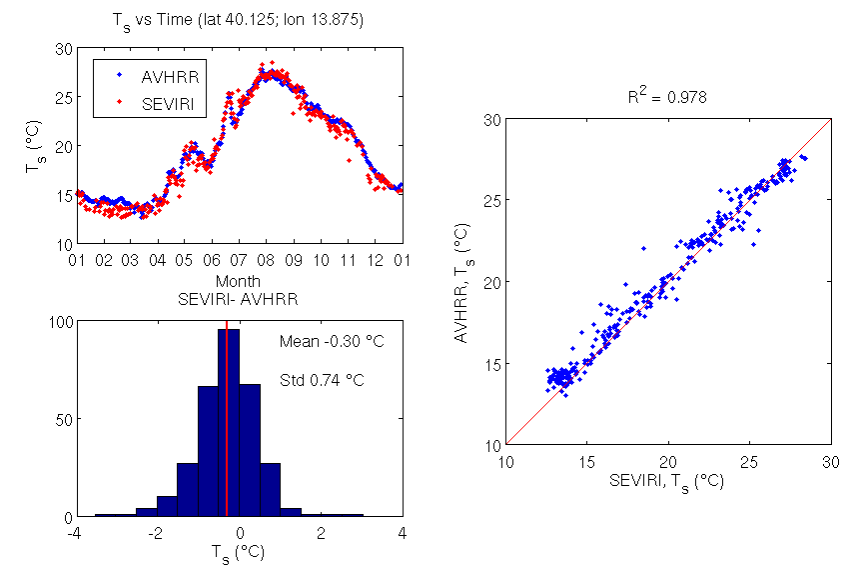

Figure 16. Year 2013. Comparison of daily values of $T_{\mathrm{S}}$ derived from SEVIRI and AVHRR. Clockwise from top left, time series of daily mean of $T_{\mathrm{S}}$, scatter plot, and histogram of the SEVIRIAVHRR difference.

2007), which, of course, cannot resolve the daily cycle. Because of the geostationary orbit, SEVIRI products do not suffer from this problem.

The comparison is shown in Fig. 16 and refers to one single SEVIRI pixel centred at lat-long coordinates $\left(40.625^{\circ} \mathrm{N}\right.$, $\left.13.875^{\circ} \mathrm{E}\right)$. This pixel is located in the north-west corner of the target area shown in Fig. 3, within the Gulf of Naples. Figure 16 shows the time evolution, over the year, for the daily mean surface temperature obtained from SEVIRI and AVHRR OI SST analysis. The shown SEVIRI KF $T_{\mathrm{S}}$ have been obtained by daily averaging of the SEVIRI retrievals (recalling that the KF approach provides retrieval on a time step of $15 \mathrm{~min}$ ).

The comparison show excellent agreement as far as the dynamics of the yearly cycle are concerned. However, the analysis also evidences a yearly negative bias of SEVIRI of $-0.30^{\circ} \mathrm{C}$, which can be compared to the value of $\approx-0.07^{\circ} \mathrm{C}$ obtained with MODIS and the ECMWF analysis. This can be explained because the AVHRR OI SST is a bulk temperature estimate, whereas the KF $T_{\mathrm{S}}$ provides an estimation of the skin temperature.

As said before, within the OI SST scheme, AVHRR satellite data undergo a de-bias procedure based on ship and buoy direct measurements, which transforms the satellite temperature from the skin to the surface of the ocean (Reynolds et al., 2007). From Fig. 16 we can see that the negative bias is quite homogeneous during the year, because SEVIRI senses the cool skin at the surface, whereas buoys measure the warmer layer just below the surface. It is also important to stress that the bias we have found $(-0.30 \mathrm{~K})$ is consistent with the well- 


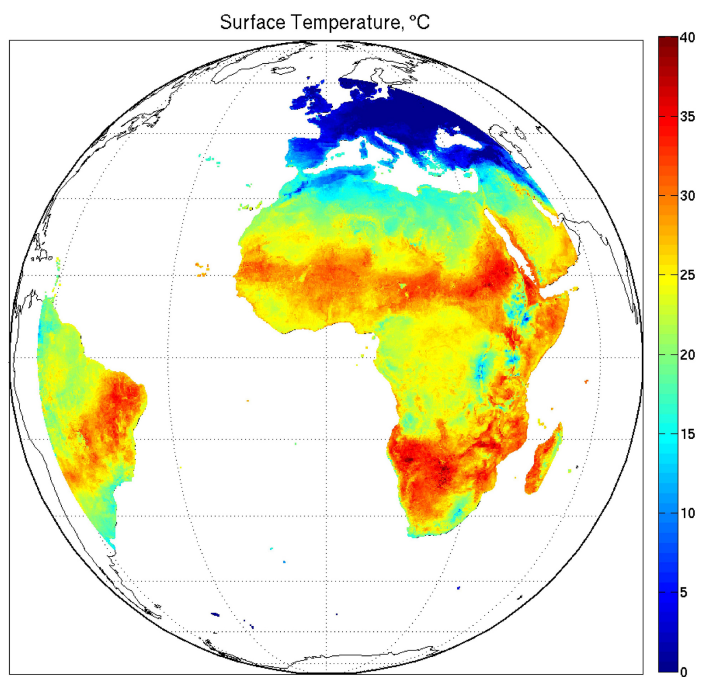

Figure 17. November 2007 map of $T_{\mathrm{S}}$ over the SEVIRI full disk.

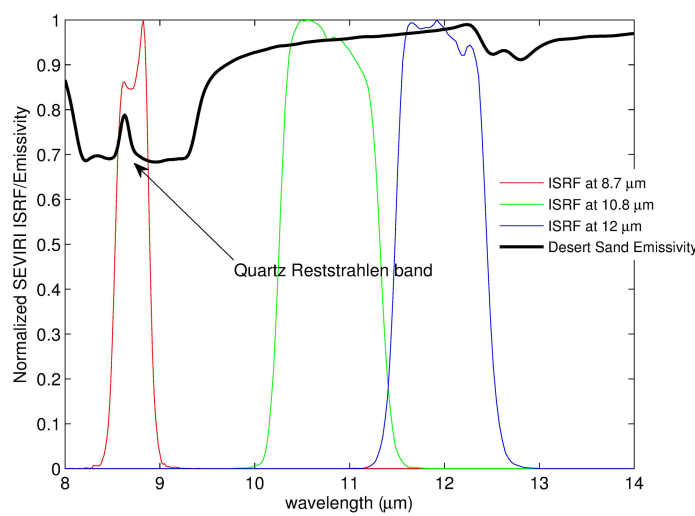

Figure 18. Typical desert sand emissivity (Baldridge et al., 2009) compared to the SEVIRI ISRF of the three atmospheric window channels.

assessed result (e.g. Schluessel et al., 1990) that the difference between bulk and skin temperature is within $\pm 1 \mathrm{~K}$ with a mean difference ranging from 0.1 to $0.3 \mathrm{~K}$.

\subsection{SEVIRI full-disk maps}

Finally, we come to the application of the KF approach to the SEVIRI full disk as defined in Fig. 1. The full-disk retrieval exercise is here mostly intended to show that the methodology can really be run at any location and its stability does not depend on time-space. For this case study, we have limited ourselves to consider the average mean field of emissivity and $T_{\mathrm{s}}$ for November 2007.

The retrieval exercise considers land surface alone, since the case of sea surface is rather straightforward, as demonstrated, for example, in Sect. 4.3.

Figure 17 shows the map for the case of surface temperature. It is seen that the map recovers the correct latitudi-

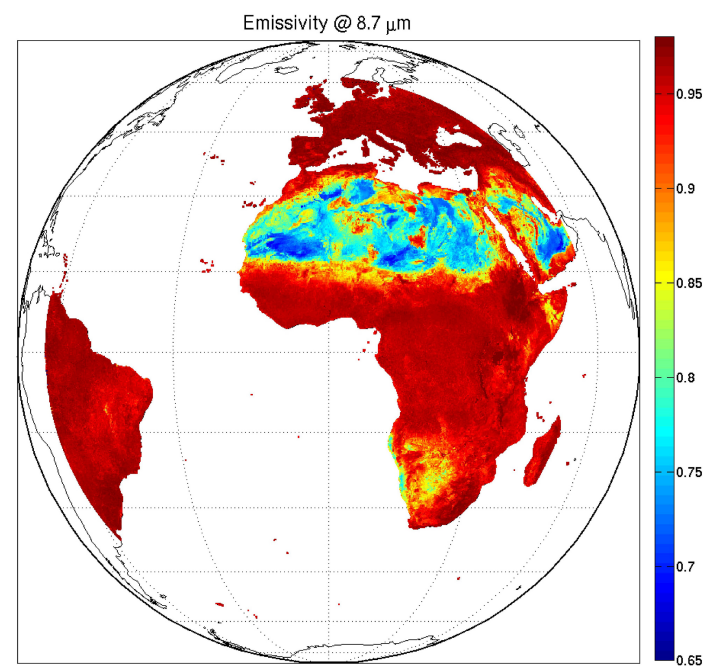

Figure 19. November 2007 map of channel emissivity at $8.7 \mu \mathrm{m}$ over the SEVIRI full disk.

nal gradient and shows the expected increase of temperature over the Sahara and the Arabian Desert. If we consider the retrieval at the border of the $\pm 70^{\circ}$ viewing angle circle, we cannot see any important problems for the eastern part of the disk. The expected warmer area of the Arabian Peninsula is correctly retrieved. However, over the western part of South America, the temperature seems too low, which could be an effect of the SEVIRI point spread function at this large angle. However, at this stage we do not have enough evidence to conclude that the full-disk area should be confined to smaller viewing angles.

As exemplified in Fig. 18, the SEVIRI channel at $8.7 \mu \mathrm{m}$ peaks in the reststrahlen band of quartz particles, and therefore it is extremely sensitive to the presence of desert sand in the SEVIRI scene. The channel can be used to map the desert area over the globe. In fact, in Fig. 19 we can nicely see the sand seas characterizing the Sahara and the Arabian Desert.

For completeness, Figs. 20 and 21 also show the emissivity maps at 10.8 and $12 \mu \mathrm{m}$, respectively. It is seen that the emissivity at 10.8 and $12 \mu \mathrm{m}$, as expected, has less contrast than that at $8.7 \mu \mathrm{m}$. The emissivity at 10.8 and $12 \mu \mathrm{m}$ are much more dependent on vegetation growth (higher emissivity for green and lower values for senescent vegetation) and hence shows, as expected, higher values over regions with evergreen forests (e.g. the African rainforest) and lower emissivities for regions corresponding to bare soil or senescent vegetation. Lower-emissivity regions are also seen in south-eastern Africa and western Madagascar. However, these emissivities are in agreement with the vegetation state in November as confirmed also by normalized differential vegetation index (NDVI) maps, which for those regions, in November, show an NDVI below 0.1 (e.g. http://www.ospo.noaa.gov/Products/land/vhp/vhp_ images.html?product=NDVI). 


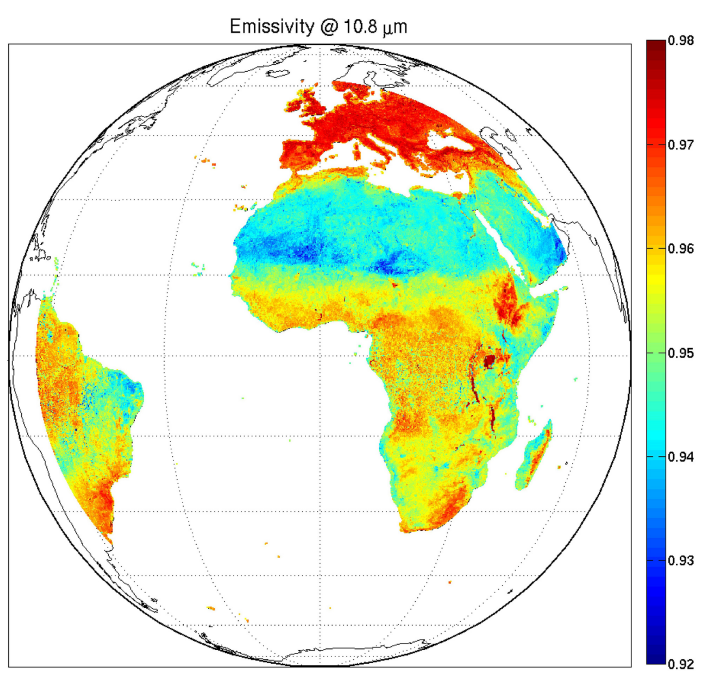

Figure 20. November 2007 map of channel emissivity at $10.8 \mu \mathrm{m}$ over the SEVIRI full disk.

To conclude this section, we will show a comparison with the UW/BFEMIS database for November 2007. Once again, we stress that UW/BFEMIS emissivities have been re-mapped to SEVIRI using a high-spectral-resolution algorithm as described in Sect. 2.2.

The comparison in Fig. 22 shows that the differences are well confined within \pm 0.05 . At $8.7 \mu \mathrm{m}$ the larger differences correspond to the desert regions, e.g. the Sahara. Desert regions are those with the higher variability at $8.7 \mu \mathrm{m}$, and therefore these differences are expected. For the channel at $10.8 \mu \mathrm{m}$ the emissivity difference is uniformly close to zero, the same as for the channel at $12 \mu \mathrm{m}$. However, at $12 \mu \mathrm{m}$ a consistent area is seen in the subtropical region of both Africa and South America, where the emissivity difference can reach values as large as $\approx 0.03$. For these regions, in November, AVHRR-based NDVI maps also show a large spatial variability with NDVI, which can drop below 0.1 . This difference between SEVIRI and UW/BFEMIS is currently under investigation.

\section{Conclusions}

We have developed and implemented a time dimension KF scheme which is capable of retrieving surface temperature and emissivity from SEVIRI channels with improved accuracy. The algorithm has been demonstrated for the SEVIRI atmospheric window channels at 12.0, 10.8 and $8.7 \mu \mathrm{m}$ and applied to a series of case studies which include land, ocean, and a large variety of climate and weather conditions.

Based on these case studies we have shown that the implementation of the KF scheme we have developed is robust and is not driven to instability by large and persistent data voids due to clouds and other anomalous events. The many

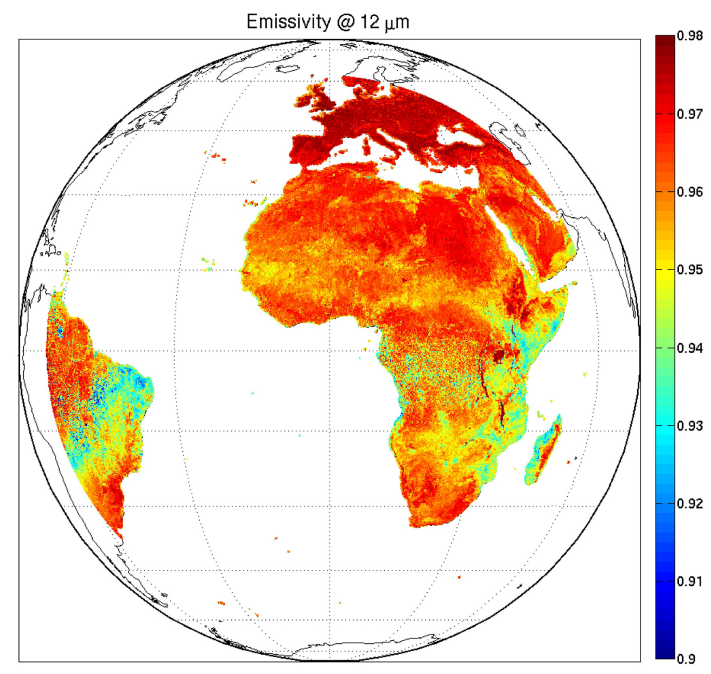

Figure 21. November 2007 map of channel emissivity at $12 \mu \mathrm{m}$ over the SEVIRI full disk.

case studies we have performed and described have shown the following:

- $T_{\mathrm{S}}$ for land surface, based on the Evora and Gobabeb validation station) $T_{\mathrm{s}}$, can be estimated with a rms error of $\approx 1.8^{\circ} \mathrm{C}$ for vegetated areas and $\approx 1.2^{\circ} \mathrm{C}$ for homogeneous arid surface. Comparison with validation stations (Evora and Gobabeb) shows a bias of less than $1{ }^{\circ} \mathrm{C}$.

- $T_{\mathrm{S}}$ for sea surface can be estimated with a rms error better than $1{ }^{\circ} \mathrm{C}$. Comparison with ECMWF, MODIS and AVHRR OI SST products for $T_{\mathrm{s}}$ shows that the bias is nearly zero.

- For sea and land surface temperature the scheme has proven capable of correctly following the daily and seasonal cycles.

- For land surface emissivity, the approach has proven to be capable of retrieving the seasonal cycle due to vegetation growth and also capable of revealing shorttimescale fluctuations of emissivity over a desert site.

- The retrieval system is robust and is not affected by large data voids, and it can rapidly recover in the case of anomalous events, which include natural phenomena and/or bad data as well.

- The scheme can be safely applied to the SEVIRI full disk, and we have derived the very first SEVIRI fulldisk emissivity maps at $12,10.8$ and $8.7 \mu \mathrm{m}$.

It should be stressed that, although based on a fully physical scheme which solves and inverts the radiative transfer equation with the accuracy of a monochromatic forward model, the software tool we have developed is very fast. Its 

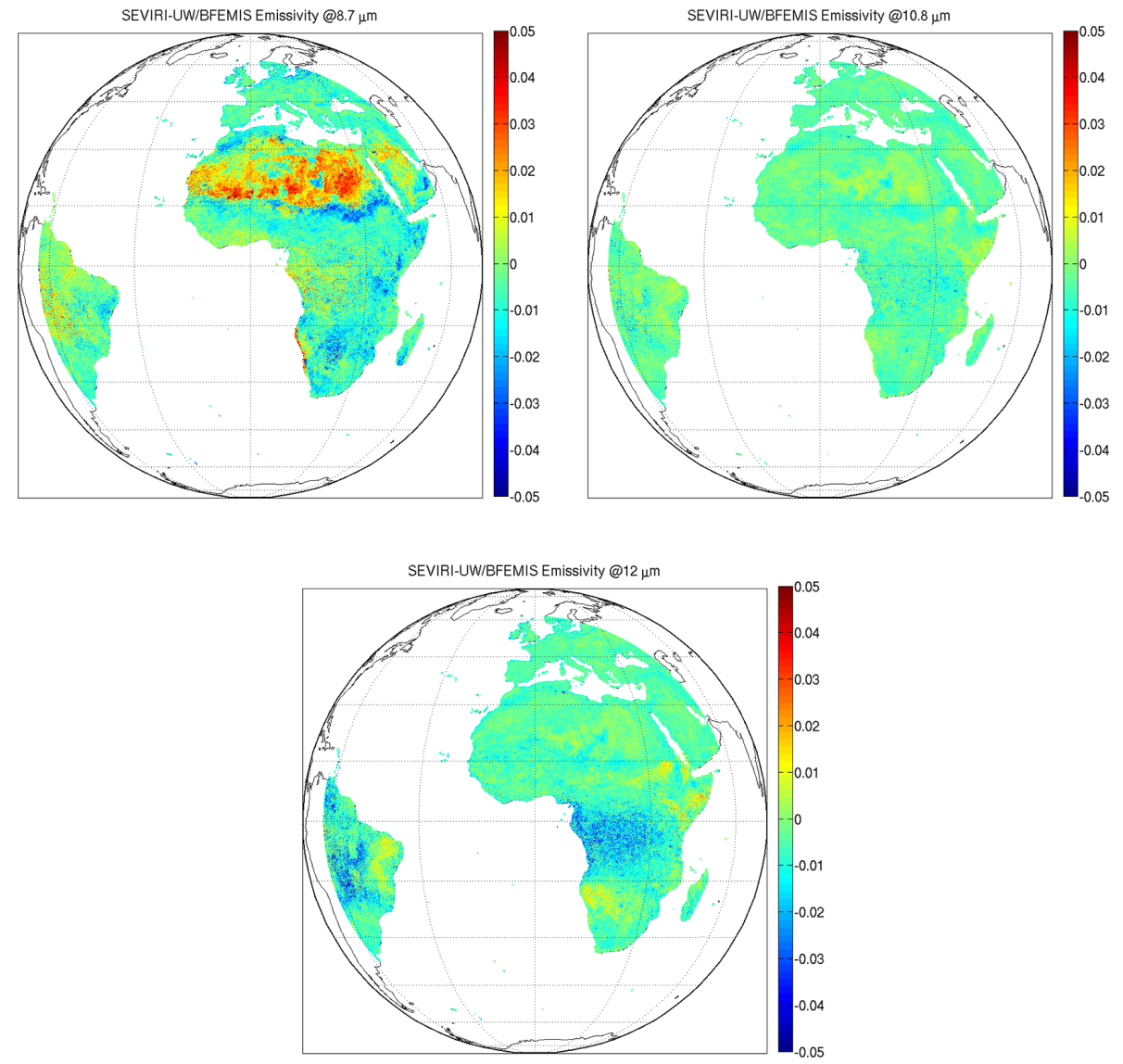

Figure 22. November 2007. Full-disk emissivity difference map (SEVIRI-UW/BFEMIS) for the channels at $8.7 \mu \mathrm{m}$ (top left), $10.8 \mu \mathrm{m}$ (top right) and $12 \mu \mathrm{m}$ (bottom).

computational performance has been tested on a quad-core Intel processor with a clock frequency of $2.7 \mathrm{GHz}$ and $1 \mathrm{~GB}$ of RAM. The time needed to process one single pixel for a single SEVIRI time slot of $15 \mathrm{~min}$ is $0.04 \mathrm{~s}$. With a single processor the time needed to run over a regional area, such as that shown in Fig. 3 (which is made up of 9643 SEVIRI pixels), would be only 6 min per SEVIRI scene. Since each scene is acquired in a time slot of $15 \mathrm{~min}$, this opens the way to the very first fully physical retrieval scheme for real-time continuous monitoring of surface parameters, which could be used for the various purposes of tourism and agronomy, land surveillance, and natural hazard and risk assessment analysis.

For offline applications, the scheme can also quickly process the SEVIRI full disk for $\left(T_{\mathrm{S}}, \epsilon\right)$. Considering that the scheme processes only clear sky (about $20 \%$ of SEVIRI pixels at the global scale), a run to process one single month (the study has considered the month of November) would take $\approx 10$ days with 100 processor units. Therefore, a global scale satellite data centre, such as EUMETSAT or LSA SAF, could release monthly maps of surface emissivity and temperature in near-real time. The emissivity maps could be used as additional input for land use/land cover change analyses and would be beneficial for many $T_{\mathrm{S}}$ statistical retrieval algorithms for SEVIRI, which largely rely on the availability of the channel emissivity at 10.8 and $12 \mu \mathrm{m}$. This availability would improve the exploitation of the European geostationary platforms and also lead to a better exploitation and improved usage of other European satellite systems.

Acknowledgements. We would like to thank the three anonymous referees for their helpful comments and remarks, which greatly helped us to improve the quality of the paper. This work was partially supported through EUMETSAT contract EUM/CO/11/4600000996/PDW and project Ritmare-Ricerca Italiana per il Mare (CNR-MIUR). Part of Fig. 2 and the entire Fig. 3 were reproduced from Google ${ }^{\mathrm{TM}}$ Earth.

Edited by: F. Prata 


\section{References}

Amato, U., Masiello, G., Serio, C., and Viggiano, M.: The $\sigma$ IASI code for the calculation of infrared atmospheric radiance and its derivatives, Environ. Modell. Softw., 17, 651-667, doi:10.1016/S1364-8152(02)00027-0, 2002.

Baldridge, A. M., Hook, S. J., Grove, C. I., and Rivera, G.: The ASTER Spectral Library version 2.0, Remote Sens. Environ., 113, 711-715, doi:10.1016/j.rse.2008.11.007, 2009.

Borbas, E. E. and B. C. Ruston: The RTTOV UWiremis IR land surface emissivity module, Document NWPSAF-MO-VS-042, EUMETSAT, Darmstadt, Germany, 2010.

Carissimo, A., De Feis, I., and Serio, C.: The physical retrieval methodology for IASI: the $\delta$-IASI code, Environ. Modell. Softw., 20, 1111-1126, doi:10.1016/j.envsoft.2004.07.003, 2005.

Ermida, S. L., Trigo, I. F., DaCamara, C. C., Göttsche, F. M., and Olesen, F. S.: Validation of remotely sensed surface temperature over an oak woodland landscape - the problem of viewing and illumination geometries, Remote Sens. Environ., 148, 16-27, 2014

Freitas, S. C., Trigo, I. F., Bioucas-Dias, J. M., and Gottsche, F.M.: Quantifying the uncertainty of land surface temperature retrievals from SEVIRI/Meteosat, IEEE T. Geosci. Remote, 48, 523-534, doi:10.1109/TGRS.2009.2027697, 2010.

French, A. N., Schmugge, T. J., and Kustas, W. P.: Discrimination of Senescent Vegetation Using Thermal Emissivity Contrast, Remote Sens. Environ., 74, 249-254, 2000.

Herman, B. M., Ben-David, A., and Thome, K. J.: Numerical technique for solving the radiative transfer equation fro a spherical shell atmosphere, Appl. Optics, 33, 1760-1770, 1994.

Gillespie, A. R., Matsunaga, T., Rokugawa, S., and Hook, S. J.: Temperature and emissivity separation from Advanced Spaceborne Thermal Emission and Reflection Radiometer (ASTER) images, IEEE T. Geosci. Remote, 36, 1113-1126, 1998.

Göttsche, F. M. and Hulley, G. C.: Validation of six satelliteretrieved land surface emissivity products over two land cover types in a hyper-arid region, Remote Sens. Environ., 124, 149$158,2012$.

Göttsche, F. M., Olesen, F. S., and Bork-Unkelbach, A.: Validation of land surface temperature derived from MSG/SEVIRI with in situ measurements at Gobabeb, Namibia, Int. J. Remote Sens., 34, 3069-3083, 2013.

Grieco, G., Masiello, G., Matricardi, M., Serio, S., Summa, D., and Cuomo, V.: Demonstration and validation of the $\varphi$-IASI inversion scheme with NAST-I data, Q. J. Roy. Meteor. Soc., 133, 217-232, doi:10.1002/qj.162, 2007.

Guillevic, P. C., Bork-Unkelbach, A., Göttsche, F. M., Hulley, G., Gastellu-Etchegorry, J. P., Olesen, F. S., and Privette, J. L.: Directional viewing effects on satellite land surface temperature products over sparse vegetation canopies - a multisensor analysis, IEEE T. Geosci. Remote, 10, 1464-1468, 2013.

Hilton, F., Armante, R., August, T., Barnet, C., Bouchard, A., Camy-Peyret, C., Capelle, V., Clarisse, L., Clerbaux, C., Coheur, P. F., Collard, A., Crevoisier, C., Dufour, G., Edwards, D., Faijan, F., Fourrié, N., Gambacorta, A., Goldberg, M., Guidard, V., Hurtmans, D., Illingworth, S., Jacquinet-Husson, N., Kerzenmacher, T., Klaes, D., Lavanant, L., Masiello, G., Matricardi, M., McNally, A., Newman, S., Pavelin, E., Payan, S., Péquignot, E., Peyridieu, S., Phulpin, T., Remedios, J., Schlüssel, P., Serio, C., Strow, L., Stubenrauch, C., Taylor, J., Tobin, D., Wolf, W., and Zhou, D.: Hyperspectral Earth Observation from IASI: four years of accomplishments, B. Am. Meteorol. Soc., 93, 347-370, doi:10.1175/BAMS-D-11-00027.1, 2012.

Kalman, R.E: A new approach to linear filtering and prediction problems, J. Basic Eng.-T. ASME, 82, 35-45, 1960.

Kalman, R. E. and Bucy, R. S.: New results in linear filtering and prediction theory, J. Basic Eng.-T. ASME, 83, 95-107, 1961.

Li, J., Li, Z., Jin, X., Schmit, T. J., Zhou, L., and Goldberg, M.: Land surface emissivity from high temporal resolution geostationary infrared imager radiances: 1 . Methodology and simulation studies, J. Geophys. Res., 116, D01304, doi:10.1029/2010JD014637, 2011.

Li, Z., Li, J., Li, Y., Zhang, Y., Schmit, T. J., Zhou, L., Goldberg, M. D., and Menzel, W. P.: Determining diurnal variations of land surface emissivity from geostationary satellites, J. Geophys. Res., 117, D23302, doi:10.1029/2012JD018279, 2012.

Li, Z.-L., Tang, B.-H., Wu, H., Ren, H., Yan, G., Wan, Z., Isabel, F. Trigo, I. F., and Sobrino, J. A.: Satellite-derived land surface temperature: current status and perspectives, Remote Sens. Environ., 131, 14-37, doi:10.1016/j.rse.2012.12.008, 2013.

Masiello, G. and Serio, C.: Simultaneous physical retrieval of surface emissivity spectrum and atmospheric parameters from Infrared Atmospheric Sounder Interferometer spectral radiances, Appl. Optics, 52, 2428-2446, doi:10.1364/AO.52.002428, 2013.

Masiello, G., Serio, C., Carissimo, A., Grieco, G., and Matricardi, M.: Application of $\varphi$-IASI to IASI: retrieval products evaluation and radiative transfer consistency, Atmos. Chem. Phys., 9, 8771-8783, doi:10.5194/acp-9-8771-2009, 2009.

Masiello, G., Serio, C., Deleporte, T., Herbin, H., Di Girolamo, P., Champollion, C., Behrendt, A., Bosser, P., Bock, O., Wulfmeyer, V., Pommier, M., and Flamant, C.: Comparison of IASI water vapour products over complex terrain with COPS campaign data, Meteorol. Z., 22, 471-487, doi:0.1127/09412948/2013/0430, 2013a.

Masiello, G., Serio, C., De Feis, I., Amoroso, M., Venafra, S., Trigo, I. F., and Watts, P.: Kalman filter physical retrieval of surface emissivity and temperature from geostationary infrared radiances, Atmos. Meas. Tech., 6, 3613-3634, doi:10.5194/amt-63613-2013, 2013b.

Masiello, C., Serio, C., Venafra, S., De Feis, I., Borbas, E. E.: DayNight variation of Sahara desert sand emissivity during the dry season from IASI observations, J. Geophys. Res., 119, 16261638, doi:10.1002/jgrd.50863, 2014.

Masuda, K., Takashima, T., and Takayama, Y.: Emissivity of pure and sea waters for the model sea surface in the infrared window regions, Remote Sens. Environ., 24, 313-329, 1988.

Matsunaga, T.: A temperature-emissivity separation method using an empirical relationship between the mean, the maximum, and the minimum of the thermal infrared emissivity spectrum, Jour. Remote Sens. Soc. Japan, 14, 230-241, 1994 (in Japanese with English abstract).

Nychka, D. W. and Anderson, J. L.: Data Assimilation. Handbook of Spatial Statistics, edited by: Gelfand, A., Diggle, P., Guttorp, P., and Fuentes, M., Chapman \& Hall/CRC, New York, USA. 2010.

Reynolds, R. W., Smith, T. M., Liu, C., Chelton, D. B., Casey, K. S., and Schlax, M. G.: Daily high-resolution-blended analyses for sea surface temperature, J. Climate, 20, 5473-5496, 2007. 
Rodgers, C. D.: Inverse Methods for Atmospheric Sounding, Theory and Practice World Scientific, Singapore, 2000.

Rozenstein, O., Agam, N., Serio, C., Masiello, G., Venafra, S., Achal, S., Puckrin, E., and Karnieli, A.: Diurnal emissivity dynamics in bare versus biocrusted sand dunes, Sci. Total Environ., 506, 422-429, 2015.

Schluessel, P., Emery, W. J., Grassl, H. and Mammen, T.: On the bulk-skin temperature difference and its impact on satellite remote sensing of sea surface temperature, J. Geophys. Res., 13341-13356, doi:10.1029/JC095iC08p13341, 1990.

Seemann, S. W., Borbas, E. E., Knuteson, R. O., Stephenson, G. R., and Huang, H. L.: Development of a Global Infrared Land Surface Emissivity Database for Application to Clear Sky Sounding Retrievals from Multispectral Satellite Radiance Measurements, J. Appl. Meteorol. Clim., 47, 108-123, doi:10.1175/2007JAMC1590.1, 2007.

Serio, C., Masiello, G., Amoroso, M., Venafra, S., Amato, U., and De Feis, I.: Study on Space-Time Constrained Parameter Estimation from Geostationary Data, Final Progress Report, EUMETSAT contract No. EUM/CO/11/4600000996/PDW, 2013.

Serio, C., Masiello, G., Amoroso, M., Venafra, S., Amato, U., and De Feis, I.: Kalman Filter estimation of surface temperature and emissivity from SEVIRI, Final Report, EUMETSAT contract No. EUM/CO/14/4600001329/PDW, 2014.

Tarantola, A.: Inverse Problem Theory: Methods for Data Fitting and Model Parameter Estimation, Elsevier, New York, USA, 1987.
Theocharous, E., Usadi, E., and Fox, N. P.: CEOS Comparison of IR Brightness Temperature Measurements in Support of Satellite Validation, Part I: Laboratory and Ocean Surface Temperature Comparison of Radiation Thermometers, NPL REPORT OP3, Technical Report ISSN: 1754-2944, National Physical Laboratory, Teddington, UK, 2010.

Trigo, I. F., Monteiro, I. T., Olesen, F., and Kabsch, E.: An assessment of remotely sensed land surface temperature, J. Geophys. Res., 113, D17108, doi:10.1029/2008JD010035, 2008a.

Trigo, I. F., Peres, L. F., DaCamara, C. C., and Freitas, S. C.: Thermal land surface emissivity retrieved from SEVIRI/Meteosat, IEEE T. Geosci. Remote, 46, 307-315, 2008b.

Wikle, C. K. and Berliner, L. M.: A Bayesian tutorial for data assimilation, Physica D, 230, 1-16, 2007.

Wulfmeyer, V., Bauer, H., Di Girolamo, P., and Serio, C.: Comparison of active and passive water vapor remote sensing from space: an analysis based on the simulated performance of IASI and space borne differential absorption lidar, Remote Sens. Environ., 95, 211-230, 2005.

Xu, H., Yu, Y., Tarpley, D., Göttsche, F. M., and Olesen, F. S.: Evaluation of GOES-R land surface temperature algorithm using SEVIRI satellite retrievals with in situ measurements, IEEE T. Geosci. Remote, 52, 3812-3821, 2014. 